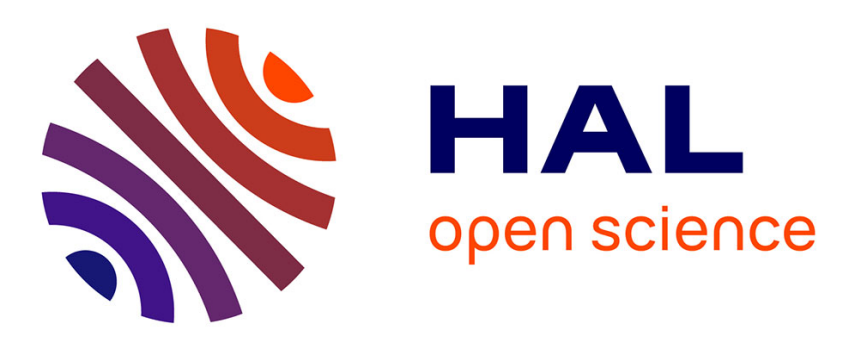

\title{
Design of a multimode interferometer-based mid-infrared multispecies gas sensor
}

\author{
Loïc Bodiou, Yannick Dumeige, Simone Normani, Geoffrey Louvet, Petr \\ Nemec, Virginie Nazabal, Joël Charrier
}

\section{To cite this version:}

Loïc Bodiou, Yannick Dumeige, Simone Normani, Geoffrey Louvet, Petr Nemec, et al.. Design of a multimode interferometer-based mid-infrared multispecies gas sensor. IEEE Sensors Journal, 2020, 20 (22), pp.13426-13435. 10.1109/JSEN.2020.3005346 . hal-02936794

\section{HAL Id: hal-02936794 \\ https://hal.science/hal-02936794}

Submitted on 18 Jan 2021

HAL is a multi-disciplinary open access archive for the deposit and dissemination of scientific research documents, whether they are published or not. The documents may come from teaching and research institutions in France or abroad, or from public or private research centers.
L'archive ouverte pluridisciplinaire HAL, est destinée au dépôt et à la diffusion de documents scientifiques de niveau recherche, publiés ou non, émanant des établissements d'enseignement et de recherche français ou étrangers, des laboratoires publics ou privés. 
$<$

\begin{abstract}
A $1 \times 2$ multimode interferometer beam splitter based on mid-infrared emitting chalcogenides waveguides is designed. This device multiplexes mid-infrared light in two channels whose respective passbands overlap either $\mathrm{CO}_{2}$ or $\mathrm{CO}$ absorption bands, respectively between $4.20-4.32 \mu \mathrm{m}$ and 4.50$4.86 \mu \mathrm{m}$. The proposed device offers a low-cost solution for monolithic combination of broadband on-chip mid-infrared light emission with dispersive spectroscopic element devoted to mid-IR multigas sensing applications. Based on restrictive interference mechanism in a $1 \times 2$ multimode interferometer, the multimode section dimensions (width and length) are engineered to increase the imbalance between the two ports for the two passbands and consequently to increase the output contrast ratio. Tolerances to variations from the optimum device design resulting from processing conditions (materials fabrication and sputtering, photolithography and dry etching steps) are assessed. In particular, the $1 \times 2$ multimode interferometer diplexer spectral transmission is investigated as a function of deposited film refractive index and multimode section dimensions (width and length) deviation from designed values. Input and output ports tapering is introduced to reduce the device insertion loss.
\end{abstract}

Index Terms-Amorphous materials, Chalcogenides thin films, Environmental monitoring, Infrared spectroscopy, Integrated circuit design, Luminescent devices, Mid-Infrared sensors, Optical strip waveguides components, Photonic Integrated Circuits, And Praseodymium

\section{INTRODUCTION}

MID-INFRARED (mid-IR) integrated sensing of liquids and gases [1] has found applications as diverse as environmental monitoring and pollutant detection (smoke and greenhouse gases detection [2], emerging water pollutant identification [3]), military and homeland security (detection of drugs [4] and hazardous materials [5]) but also industrial and healthcare (food processing industry, pharmaceutical and medical products identification [6]).

Different bulk optical components (modulator, splitter or polarizer) have been transposed in photonic integrated circuits (PIC) thanks to technical advancements witnessed in the last two decades. In particular, recent advancements have associated both the mid-IR light source (Quantum Cascade Lasers or QCL) and waveguides [7]-[9] or transducer and detector [2] on the same chip. However, monolithic integration of a complete sensing platform combining a

L. Bodiou, Y. Dumeige and J. Charrier are with Univ Rennes, CNRS, Institut FOTON - UMR 6082, F-22305 Lannion, France (e-mail: Loic.Bodiou@univ-rennes1.fr, Y Yannick.Dumeige@univ-rennes1.fr, Joel.Charrier@univ-rennes1.fr),

G. Louvet and V. Nazabal are with Univ Rennes, CNRS, ISCR (Institut des Sciences Chimiques de Rennes) - UMR 6226, F-35000 Rennes, France broadband mid-IR light source, transducer and detector is still challenging [10],[11].

To improve detection capability of photonic integrated circuits, numerous works have also targeted the miniaturization of optical spectrometers. Various configurations of Fourier Transform spectrometers, namely spatial heterodyne spectrometers (SHS) and stationary-wave integrated Fourier-transform spectrometry (SWIFTS) systems have been reported using different materials platforms including silicon [12],[13], Ge rich SiGe [14],[15], silicon nitride [16] or lithium niobate [17]. Other spectroscopic or (de)multiplexing systems based on dispersive devices such as array waveguide gratings (AWG) [18]-[20] planar concave gratings (also known as echelle grating) [21]-[23] have also been demonstrated to operate in mid-IR spectral domain. Wavelength division (de)multiplexer based on multimode interferometers (MMI) have been proposed to split telecommunication wavelengths (1.3/1.55 $\mu \mathrm{m}$ [24] and 1.55/2 $\mu \mathrm{m}$ multiplexers [25]). MMI devices operating at mid-IR wavelengths have also been implemented using silicon on insulator [26],[27] suspended silicon [28] or chalcogenides [29] platforms.

As many gases, such as $\mathrm{CH}_{4}, \mathrm{CO}_{2}, \mathrm{CO}$ or $\mathrm{NO}_{\mathrm{x}}$ have strong absorption features in the mid-IR, environmental monitoring will benefit from the development of a spectroscopic sensing platform incorporating a broadband light source operating in the 3-5 $\mu \mathrm{m}$ spectral region. Rare-earth doped chalcogenides have been shown to display broadband mid-IR luminescence in integrated waveguides [30]-[32] and fibers [33]-[36] enabling remote detection of $\mathrm{CH}_{4}$ and $\mathrm{CO}_{2}$ for field operations or in situ monitoring in microfluidic system [2][4]. Therefore, monolithic association of a broadband mid-IR light source based on rare-earth doped chalcogenides with an integrated spectroscopic system made from the same materials could help the development of multi-analyte sensor systems on a chip that are expected to have a positive impact on a myriad of applications. In particular, an integrated dualgas sensor for the simultaneous detection of $\mathrm{CO}_{2}$ and $\mathrm{CO}$ gases could be advantageously used, for example, in the aeronautic industry [37]. Indeed, environmental regulations become more stringent and require the monitoring of aircraft emission to reduce greenhouse gas emission due to incomplete kerosene combustion.

(e-mail: Geoffrey.Louvet@univ-rennes1.fr, Virginie.Nazabal@univrennes1.fr)

S. Normani and P. Němec are with the Department of Graphic Arts and Photophysics, Faculty of Chemical Technology, University of Pardubice, 53210, Pardubice, Czech Republic (e-mail: Simone.Normani@iit.it, Petr.Nemec@upce.cz). 
In this paper, we report the design of a $1 \times 2 \mathrm{MMI}$ multiplexer operating in the mid-IR spectral region based on chalcogenides waveguides to develop a multispecies gas sensor. The MMI dimensions are assessed to enable the multiplexing of mid-IR broadband emission from $\mathrm{Pr}^{3+}$-doped selenides to develop a dual-gas sensor allowing simultaneous detection of $\mathrm{CO}$ and $\mathrm{CO}_{2}$ gases. The MMI multimode section dimensions are engineered to enlarge the operation bandwidth and to diplex mid-IR light on two spectral windows overlapping $\mathrm{CO}$ and $\mathrm{CO}_{2}$ absorption bands (Fig. 1), each of them coming through one of the two MMI output channels. The design robustness is then assessed over different parameters such as refractive index change or multimode section width and length variation. Finally, tapered input and output ports are introduced to further relax fabrication tolerances and to reduce device insertion optical losses.

\section{DEVICE DESIGN}

\section{A. Device operating principles}

In a conventional $1 \times 2 \mathrm{MMI}$, a single-mode input port is laterally centered in relation to the multimode section width (wмMI). Multiple optical modes are thus excited by the optical mode arising from the single-mode input. Constructive interferences between these modes give rise to single or multiple replica of the input mode in the multimode section at periodic positions along the propagation direction in a wellknown self-imaging effect [38].

Under restricted interferences regime, the input and output ports are shifted by $\pm \mathrm{w}_{\mathrm{MMI}} / 6$ with respect to the center of the multimode region width (Fig. 2). In such a case, only certain optical modes will be excited in the multimode section of the MMI. Therefore, solely direct or mirrored image of the input field will be observed along the propagation direction in the multimode section. These images will, respectively, occur at even and odd integers of the so-called beat length $L_{\pi}^{\lambda}$ defined as:

$$
L_{\pi}^{\lambda}=\frac{\pi}{\beta_{0}-\beta_{1}} \approx \frac{4 \cdot n_{e f f, 0} \cdot W_{e f f}^{2}}{3 \cdot \lambda}
$$

where $\beta_{0}$ and $\beta_{1}$ are the propagation constants for the two lowest order modes, $\mathrm{n}_{\mathrm{eff}, 0}$ is the effective refractive index of the MMI multimode region fundamental mode, $\lambda$ is the wavelength and $\mathrm{W}_{\text {eff }}$ is the effective multimode section width which can be approximated to $\mathrm{W}_{\mathrm{MMI}}$ for high contrast waveguides [38].

Based on the restricted interference mechanism in its multimode section, it is thus possible to use a MMI to separate two different wavelengths $\lambda_{1}$ and $\lambda_{2}$ incoming from the same input port into two output channels corresponding to port 1 and port 2 by forming a direct image at a given wavelength and a mirrored image at the other. To do so, the width and length of the MMI multimode section must be chosen to satisfy the following conditions [24],[25]:

$$
L_{M M I}=p \cdot L_{\pi}^{\lambda_{1}}=(p+q) \cdot L_{\pi}^{\lambda_{2}}
$$

where $\mathrm{p}$ is a positive integer, $\mathrm{q}$ is an odd integer and $L_{\pi}^{\lambda_{i}}$ is the beat length at the wavelength $\lambda_{\mathrm{i}}$ defined in (1).

In the proposed device, the MMI multimode section is designed so that the wavelengths corresponding to the absorption bands of $\mathrm{CO}_{2}$ (black shaded region in Fig. 1) will exit the MMI multimode section through one of the output ports whereas wavelengths corresponding to the absorption bands of $\mathrm{CO}$ (red shaded region in Fig. 1) will come out through the other output port.

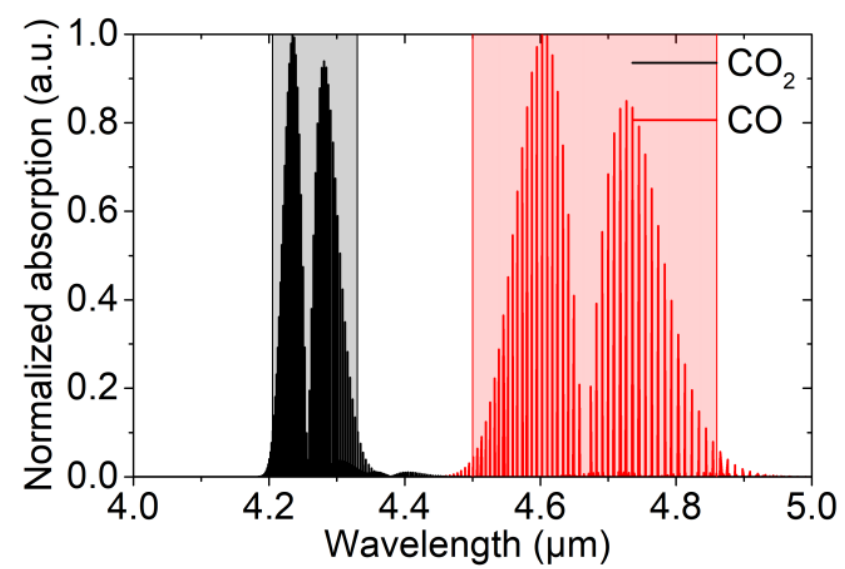

Fig. 1. Normalized absorption bands of carbon monoxide $(\mathrm{CO})$ and carbon dioxide $\left(\mathrm{CO}_{2}\right)$. The two bands to multiplex are superimposed to these spectra.

\section{B. Description of the MMI structure}

The materials platform used to design the MMI follows from [30] where Praseodymium-doped selenides films $\left(\mathrm{Ga}_{5} \mathrm{Ge}_{20} \mathrm{Sb}_{10} \mathrm{Se}_{65}: 5000 \mathrm{ppm} \mathrm{Pr}^{3+}\right)$ are deposited from glass targets prepared by means of conventional melt and quenching method [39] by radio frequency (RF) magnetron sputtering on thermally oxidized $\left(4-\mu \mathrm{m}\right.$ thick $\left.\mathrm{SiO}_{2}\right) 2$ " silicon wafer. Subsequent ridge waveguides fabrication was achieved through a classical i-line photolithographic process followed by a fluorine-based inductively coupled plasmareactive ion etching (ICP-RIE) process. Single-mode waveguiding and photoluminescence overlapping $\mathrm{CO}$ and $\mathrm{CO}_{2}$ absorption in the 4 to $5 \mu \mathrm{m}$ spectral range (Fig. 1) was previously observed [30],[40]. Fibers of the same glass composition but codoped with $\mathrm{Dy}^{3+}$ and $\mathrm{Pr}^{3+}$ enabled simultaneous detection of $\mathrm{CO}_{2}$ and $\mathrm{CH}_{4}$ [36]. The linear refractive indices used in the simulations for chalcogenide and $\mathrm{SiO}_{2}$ thin films were, respectively, obtained from the analysis of variable angle spectroscopic ellipsometry data [41] and from [42].

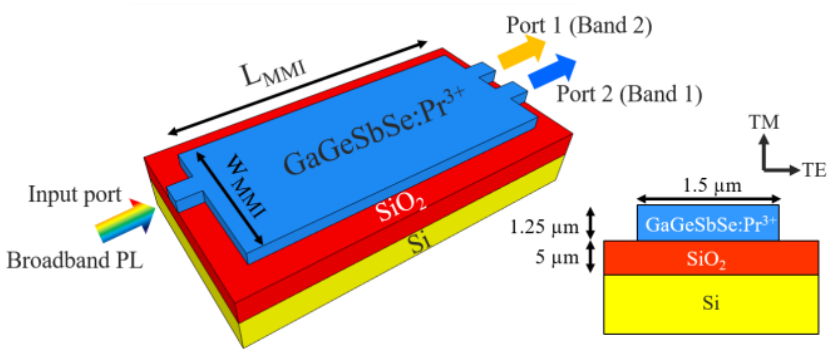

Fig. 2. Schematic representation of the multiplexing MMI structure based on $\mathrm{GaGeSbSe}: \mathrm{Pr}^{3+}$. The cross-section of the input port is displayed on the right

\section{MMI dimensions optimization}

Simulations were performed using the FIMMPROP propagation module integrated with FIMMWAVE software and based on the eigenmode expansion (EME) method. These computations were undertaken with a real semi-vectorial finite difference method (FDM) mode solver in TE polarization and used a $50 \mathrm{~nm} \times 50 \mathrm{~nm}$ transverse grid size.

The optimization of the MMI multimode section dimensions is aimed at obtaining a direct image for 
wavelengths used for sensing the first gas (band i) and a mirrored image for wavelengths at which the second gas absorbs (band j). In the simulations, the fundamental TE mode of the input waveguide corresponding to the crosssection displayed in Fig. 2 was launched at the MMI entrance. The transmitted power at both output ports was then monitored as a function of MMI multimode section width (wMMI) and length ( $\left.\mathrm{L}_{\mathrm{MMI}}\right)$ for different wavelengths corresponding to the absorption wavelengths of $\mathrm{CO}$ and $\mathrm{CO}_{2}$ gases. The MMI width was scanned between 10 and $50 \mu \mathrm{m}$ whereas MMI lengths ranged from 10 to $2500 \mu \mathrm{m}$ (Fig. 3).

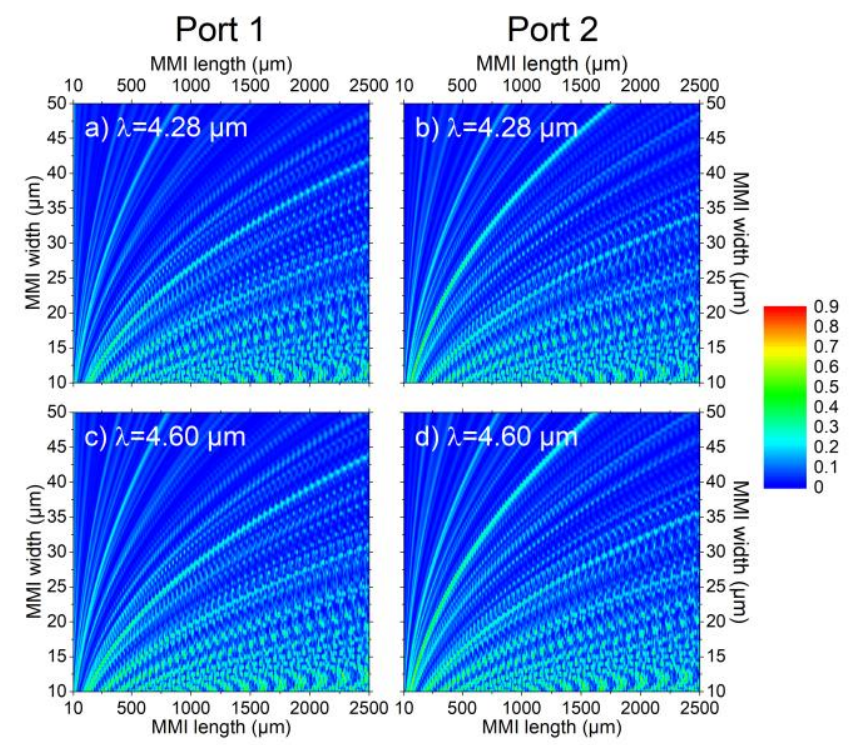

Fig. 3. Power transmission for the two output ports as a function of MMI multimode section width ( $\left.\mathrm{w}_{\mathrm{MMI}}\right)$ and length $\left(\mathrm{L}_{\mathrm{MMI}}\right)$ for two wavelengths: a), b) $4.28 \mu \mathrm{m}$ and c), d) $4.6 \mu \mathrm{m}$.

Simulation results obtained for wavelengths equal to $\lambda=4.28 \mu \mathrm{m}$ and $\lambda=4.6 \mu \mathrm{m}$ corresponding, respectively, to the wavelengths of maximum absorption from $\mathrm{CO}_{2}$ and $\mathrm{CO}$ gases are displayed in Fig. 3. From these different figures, it can be observed that, for some $\mathrm{W}_{M M I}$ and $\mathrm{L}_{\mathrm{MMI}}$, the imbalance between both ports can be high for two different wavelengths. However, in opposition to previously reported MMI-based multiplexers [24],[25], in this device, rather than single wavelengths, broad bands (150 to $350 \mathrm{~nm}$ ) have to be separated. MMI transmission on both output ports was thus simulated for different wavelengths separated by $15 \mathrm{~nm}$. Band 1 (corresponding to the black shaded area in Fig. 1) was sampled with 8 different wavelengths whereas 23 wavelengths were used for the broader second band (red shaded area in Fig. 1). The mean intensity on output ports 1

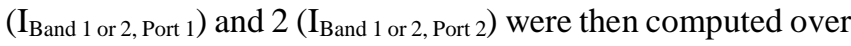
Bands 1 and 2 for each ( $\mathrm{W}_{\mathrm{MMI}}$, $\mathrm{L}_{\mathrm{MMI}}$ ) couple using the following expressions:

$$
\begin{aligned}
& I_{\text {Band } 1, \text { Port } j}=\frac{\sum_{\lambda_{i}=1}^{8} I_{\text {Port } j}^{\lambda_{i}}}{8} \\
& I_{\text {Band } 2, \text { Port } j}=\frac{\sum_{\lambda_{i}=1}^{23} I_{\text {Port } j}^{\lambda_{i}}}{23}
\end{aligned}
$$

where $j=1,2$ and corresponds to output port number (Fig. 2). The sum does not contain the same number of wavelength terms for Band 1 and Band 2 because the spacing between simulated wavelengths was kept constant even if the absorption bands have different spectral widths. No correction factors were applied to the terms of this calculation as flat-top passbands were considered to anticipate versatile device operation in terms of gas pressure or temperature resulting in absorption spectra change.

As there is no preferential output port for sensing any of the gases, the two output ports can be treated similarly. For each (WMMI, $\mathrm{L}_{\mathrm{MMI}}$ ) couple, calculations were then performed to evaluate two different ratios defined as:

$$
\begin{aligned}
S_{A} & =\frac{I_{\text {Band 1, } \text { Port } 1} \times I_{\text {Band 2, }} \text { Port } 2}{I_{\text {Band 1, }} \text { Port } 2 \times I_{\text {Band 2, }} \text { Port } 1} \\
S_{B} & =\frac{I_{\text {Band 1, } \text { Port } 2} \times I_{\text {Band } 2, \text { Port } 1}}{I_{\text {Band 1, } \text { Port } 1} \times I_{\text {Band } 2, \text { Port } 2}}
\end{aligned}
$$

Maximization of $\mathrm{S}_{\mathrm{A}}$ and $\mathrm{S}_{\mathrm{B}}$ will result in the most efficient multiplexing of broadband light source over the two channels. In scheme $\mathrm{A}$, for which $\mathrm{S}_{\mathrm{A}}$ is maximal, the wavelengths devoted to $\mathrm{CO}_{2}$ sensing (Band 1) would come out through port 1 (direct image) and wavelengths useful to detect $\mathrm{CO}$ (Band 2) would be transmitted through port 2 (mirror image). In scheme $B$, for which $S_{B}$ is maximal, the application of the two channels would be opposite.

Some ( $\mathrm{w}_{\mathrm{MMI}}, \mathrm{L}_{\mathrm{MMI}}$ ) couples enable the transmission of only a very small fraction of the incident light on one of the output ports. In that case, $S_{A}$ and $S_{B}$ can reach high values independently of the corresponding transmitted intensity through the other port. To avoid this numerical artifact, a minimum mean transmitted intensity of $35 \%$ for the through port was added as a supplementary condition to the evaluation of $\mathrm{S}_{\mathrm{A}}$ and $\mathrm{S}_{\mathrm{B}}$.

With these conditions, optimized dimensions of the MMI multimode region were found to be $\mathrm{w}_{\mathrm{MMI}}=10 \mu \mathrm{m}$ and $\mathrm{L}_{\mathrm{MMI}}=519 \mu \mathrm{m}$ (TABLE I).

TABLE I

LIST OF PARAMETERS OF OPTIMIZED MMI

\begin{tabular}{lc}
\hline \multicolumn{1}{c}{ Parameter } & Value \\
\hline Waveguide height $h$ & $1.25 \mu \mathrm{m}$ \\
Input port width $w$ & $1.5 \mu \mathrm{m}$ \\
Output ports width $w$ & $1.5 \mu \mathrm{m}$ \\
Multimode section width $w_{M M I}$ & $10 \mu \mathrm{m}$ \\
Multimode section length $L_{M M I}$ & $519 \mu \mathrm{m}$ \\
Band 1 & $4.20-4.32 \mu \mathrm{m}$ \\
Band 2 & $4.50-4.86 \mu \mathrm{m}$ \\
\hline
\end{tabular}

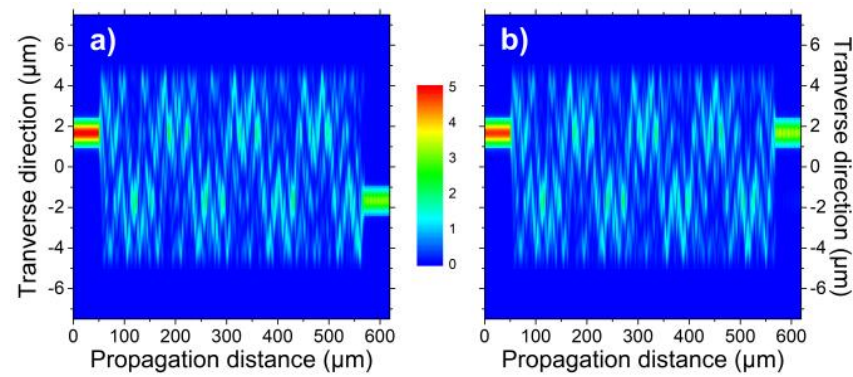

Fig. 4. Simulation of the power transmission for the MMI with optimized dimensions at a) $4.3 \mu \mathrm{m}$ and b) $4.6 \mu \mathrm{m}$.

Fig. 4 shows the power transmission through the optimized MMI for wavelengths of $4.28 \mu \mathrm{m}$ and $4.6 \mu \mathrm{m}$ that are close to the absorption maxima of $\mathrm{CO}_{2}$ and $\mathrm{CO}$, respectively. From this Fig. 4, it can be seen that mid-IR light can efficiently be multiplexed over the two different output ports using a MMI operated in the restricted interferences regime. 


\section{ROBUSTNESS TO FABRICATION TOLERANCES}

As the device performances must not be altered by fabrication imperfections, it is important that tolerances are relaxed regarding the device fabrication and processing. These relaxed tolerances concern the reproducibility and the thermal variation (thermo-optic coefficient or $\mathrm{dn} / \mathrm{dT}$ ) of the refractive index of the sputtered $\mathrm{Pr}^{3+}$-doped chalcogenides thin films but also the geometrical dimensions control during technological processing (photolithography and etching).

\section{A. Refractive index change}

Refractive index changes of the sputtered $\operatorname{Pr}^{3+}: \mathrm{GaGeSbSe}$ films can originate from various reasons. The most obvious is a variation related to the operating temperature, which will depend on the $\mathrm{dn} / \mathrm{dT}$ coefficient not well-known in case of chalcogenide thin films. Considering values of 76 and $91 \times$ $10^{-6} \mathrm{~K}^{-1}$ (respectively at wavelength of 3.4 and $10.6 \mu \mathrm{m}$ ) for the thermo-optic coefficient of $\mathrm{Ge}_{28} \mathrm{Sb}_{12} \mathrm{Se}_{60}$ glass and its thermal expansion coefficient of $14 \times 10^{-6} \mathrm{~K}^{-1}$, the $\mathrm{dn} / \mathrm{dT}$ value of the $\mathrm{Ga}_{5} \mathrm{Ge}_{20} \mathrm{Sb}_{10} \mathrm{Se}_{65}$ glass composition, which displays a thermal expansion coefficient of $16 \times 10^{-6} \mathrm{~K}^{-1}$, might be slightly lower than $91 \times 10^{-6} \pm 10 \times 10^{-6} \mathrm{~K}^{-1}$ [43],[44]. If uniformity in terms of thickness and refractive index is observed over a 2 " sample, there could be a \pm 0.01 refractive index deviation from one film to another, due to the possible slight different composition of the target from batch to batch or wear of the target during deposition. To evaluate the impact of this effect, the wavelength dependence of the transmission through the two output ports of the optimized MMI structure (TABLE I) was simulated for different refractive index changes. Results from these simulations are displayed in Fig. 5.

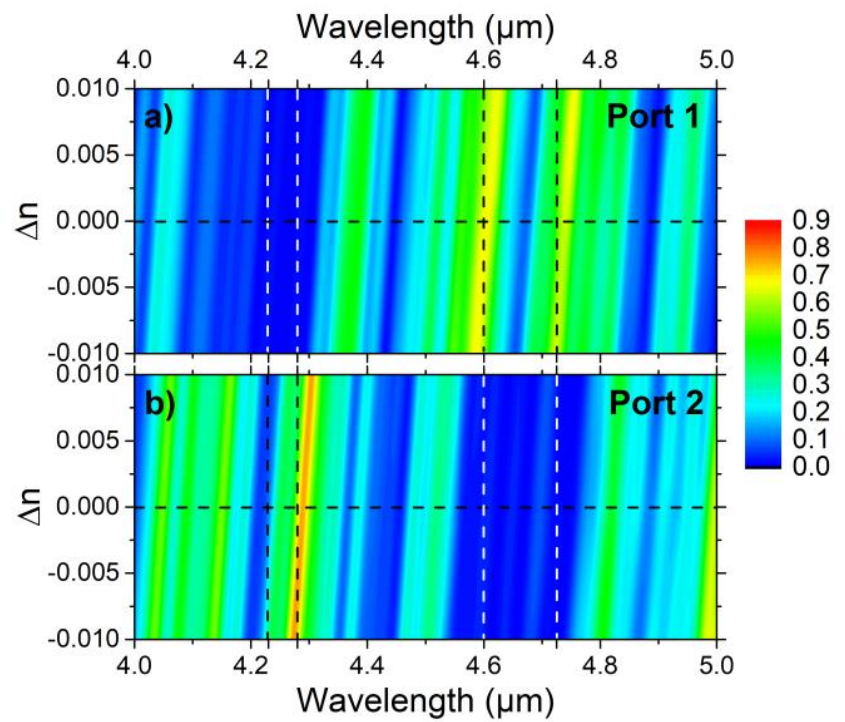

Fig. 5. Wavelength dependence of a) Port 1 and b) Port 2 transmission as a function of chalcogenide film refractive index variations $(\Delta n)$ for optimized MMI multimode section dimensions. Vertical dashed lines correspond to absorption maxima of $\mathrm{CO}_{2}$ and $\mathrm{CO}$.

Horizontal dashed lines in Fig. 5 correspond to the transmission through both output ports, respectively for Port 1 in Fig. 5a) and Port 2 in Fig. 5b), when the conventional

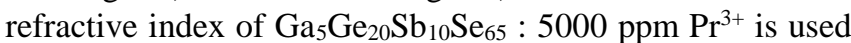
in the simulations. Dashed vertical lines in Fig. 5 correspond to the wavelengths of maximum absorption from $\mathrm{CO}$ and CO2 (Fig. 1).

From this Fig. 5, it can be confirmed that the optimized MMI dimensions enable an efficient multiplexing of $\mathrm{CO}$ - and $\mathrm{CO}_{2}$ related absorption bands through the two output ports. Indeed, a maximum of transmission over Band 1 or 2 on one port correspond a minimum of transmission of the same Band on the other port. Nonetheless, it can be noticed, in Fig. 5, that $\mathrm{CO}_{2}$ second absorption band maximum is found at $\lambda=4.28 \mu \mathrm{m}$ whereas the transmission maximum through Port 2 for MMI multimode section optimized dimensions is slightly shifted by $10 \mathrm{~nm}$ at $\lambda=4.29 \mu \mathrm{m}$. The transmission through Port 2 of the optimized device (horizontal dashed line in Fig. 5) is about $65 \%$ at $\lambda=4.28 \mu \mathrm{m}$ and reaches $76 \%$ at $\lambda=4.29 \mu \mathrm{m}$. However, to ensure device operation in different environments in terms of gas pressure or temperature which will change gas absorption spectral signature, Bands have to be considered as flat-top pass-bands and consequently their respective bandwidths must be taken into account. This is the reason why MMI structure optimization procedure, through the maximization of $\mathrm{S}_{\mathrm{A}, \mathrm{B}}$ (defined in Equations (5)-(6)), was targeting maximum transmission over a band whose bandwidth is more than $100 \mathrm{~nm}$ rather than at a specific wavelength.

From Fig. 5, it is also observed that the transmission band and bandwidth of any port are hardly affected by a moderate refractive index change up to \pm 0.01 .

\section{B. Multimode section width and length}

The effect of processing imperfections must also be assessed. Indeed, lithographic (photoresist aging, thickness or exposure variation) and etching (plasma density) steps can strongly influence the geometric parameters of processed MMI. Evaluation of the designed MMI device variability on different levels scales (intra-die, die-to-die and wafer-towafer) must therefore be performed [45]. To this end, impact of MMI multimode section length and width variations were computed (Fig. 6 and Fig. 7).

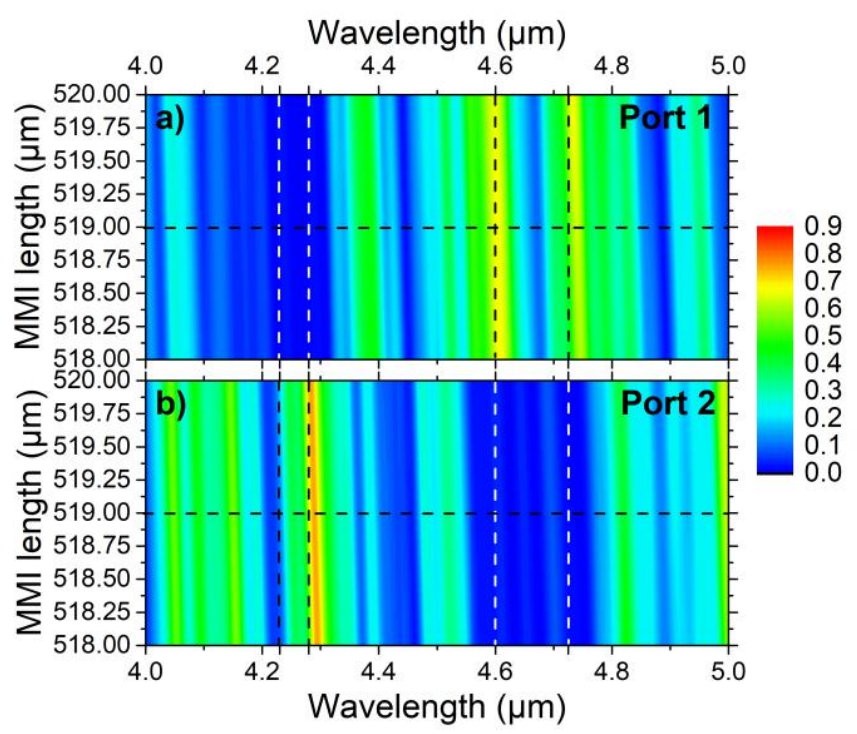

Fig. 6. Wavelength dependence of a) Port 1 and b) Port 2 transmission as a function of MMI multimode section length ( $\left.\mathrm{L}_{\mathrm{MMI}}\right)$.

From Fig. 6, it can be seen that the global shape of the color 
maps yields almost vertical lines, which means that the wavelength dependence of the transmission on both ports is rather similar for each MMI multimode section length $\mathrm{L}_{\mathrm{MMI}}$ simulated. Consequently, important variations of the MMI multimode section length hardly influences the wavelength response of the transmission. As it can be envisioned that processed devices will not suffer from such large $( \pm 1 \mu \mathrm{m})$ length variations, this parameter change is expected not to strongly affect the device performance.

The color maps presented in Fig. 7 display a very different behavior compared to those observed in Fig. 5 and Fig. 6 where vertical shapes could be seen. For example, in Fig. 7, a $200 \mathrm{~nm}$ change of $\mathrm{W}_{\mathrm{MMI}}$ (from $10 \mu \mathrm{m}$ to $9.8 \mu \mathrm{m}$ ) decreases the transmission at $4.29 \mu \mathrm{m}$ and at $4.6 \mu \mathrm{m}$, respectively through Port 2 and Port 1 , from $\sim 80 \%$ to less than $10 \%$. This spectral dependence of the multiplexing on MMI multimode section width can be explained by the corresponding effective refractive index change, which strongly impacts the beat length and thus the transmission.

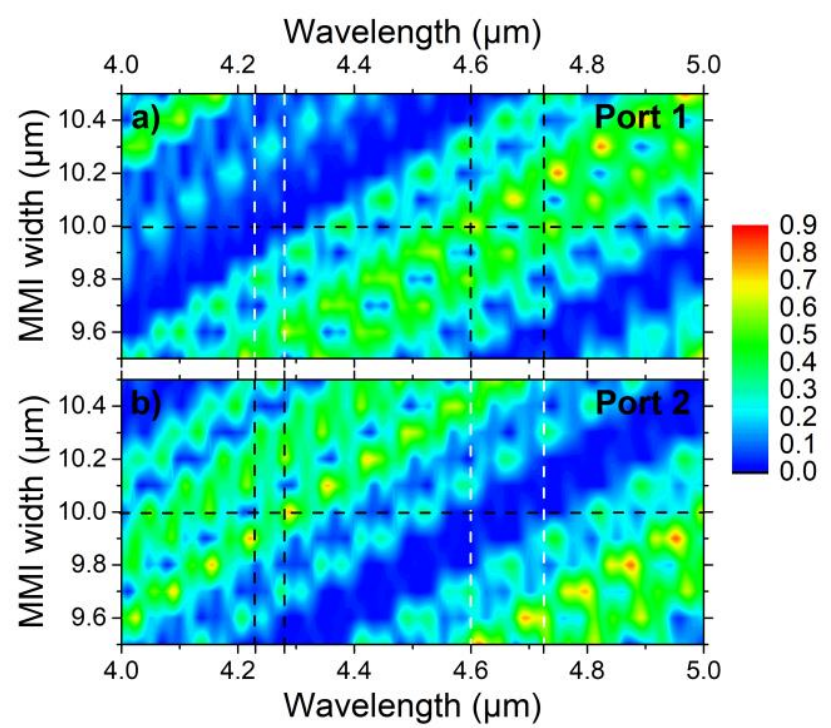

Fig. 7. Wavelength dependence of a) Port 1 and b) Port 2 transmission as a function of MMI multimode section width ( $\mathrm{w}_{\mathrm{MMI}}$ ) with straight input and output ports (ports width $=1.5 \mu \mathrm{m}$ ).

\section{Tapered input and output ports}

Tapered port implementation was demonstrated to advantageously enable device insertion loss reduction and relax the impact of fabrication errors on MMI transmission [46],[47]. To enhance device transmission and to mitigate the

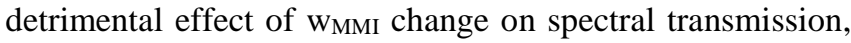
tapered input and output ports were then introduced in the simulations. The designed taper is identical on all ports (input and output) and consists of a $25-\mu \mathrm{m}$ long linear tapering of the port waveguide width. Simulation results are presented in Fig. 8 .

The taper width was scanned between $\mathrm{w}_{\text {taper }}=1.5 \mu \mathrm{m}$ to $\mathrm{w}_{\text {taper }}=3.25 \mu \mathrm{m}$. The former width corresponds to the single mode straight waveguides width whereas the latter is approximately equal to half of the distance between output ports. From Fig. 8, it can be noticed that the transmission increases globally as the taper width is enlarged. For large widths (above $\mathrm{w}_{\text {taper }}=3 \mu \mathrm{m}$ ), the pass bands widen and tend to shift relative to the absorption maxima of $\mathrm{CO}_{2}$ and $\mathrm{CO}$ (represented by the vertical dashed lines). An optimum taper width of $3 \mu \mathrm{m}$ is therefore inferred from this Fig. 8. These results are in accordance with previous reports stating that the optimum taper width with regards to transmission is $3 / 10^{\text {th }}$ of the MMI multimode width [29].

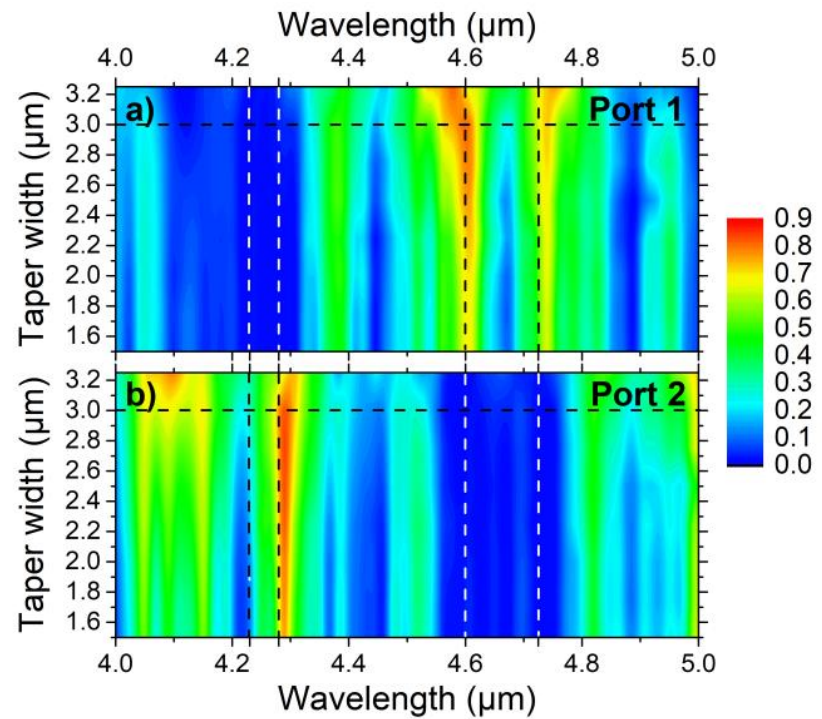

Fig. 8. Wavelength dependence of a) Port 1 and b) Port 2 transmission as a function of input and output ports taper width $\left(\mathrm{w}_{\text {taper }}\right)$.

The spectral dependence of transmission through both ports was calculated (Fig. 9) for a taper width of $\mathrm{w}_{\text {taper }}=3 \mu \mathrm{m}$ (represented by the horizontal dashed line in Fig. 8). From Fig. 9, it can be confirmed that tapering the output ports increases the overall transmission. In comparison to Fig. 7, it can also be observed that fabrication tolerances are relaxed even if the device may still be sensitive to variations larger than $\pm 100 \mathrm{~nm}$.

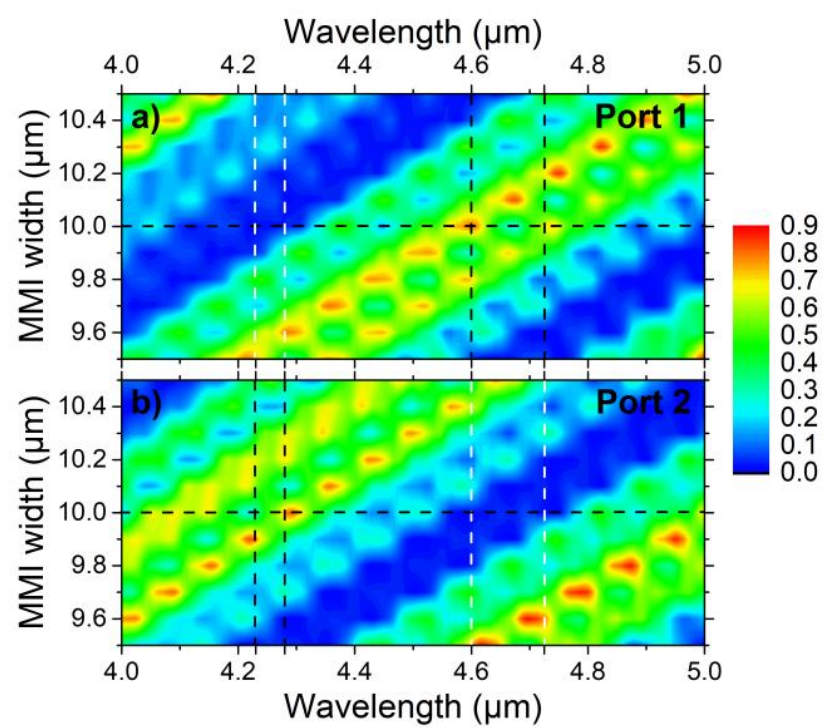

Fig. 9. Wavelength dependence of a) Port 1 and b) Port 2 transmission as a function of MMI multimode section width ( $\left.\mathrm{w}_{\mathrm{MMI}}\right)$ for an MMI with tapered input and output ports (taper width $=3 \mu \mathrm{m}$ ).

\section{CONCLUSION}

In this paper, a $1 \times 2$ MMI beam splitter based on luminescent $\mathrm{Pr}^{3+}$-doped chalcogenides thin films and operating in the 4-5.5- $\mu \mathrm{m}$ wavelength range was investigated. This device relates on restricted interferences mechanism to multiplex $\mathrm{Pr}^{3+}$ luminescence on two spectral bands overlapping $\mathrm{CO}_{2}$ and $\mathrm{CO}$ absorption bands. The device was 
designed to be scarcely affected by imperfections occuring during processing steps (chalcogenide glass target fabrication and amorphous chalcogenide thin film deposition, photolithography, ICP-RIE etching). Optimum MMI dimensions were calculated and sensibility to refractive index, MMI multimode section width and length variations were studied. Finally, MMI ports tapering were implemented to enhance the device transmission.

The proposed combination of luminescent amorphous chalcogenides thin films with spectroscopic elements could enable the development of on-chip mid-IR multi-gas sensing devices providing low-cost solution for on-field chemical analysis.

The operating principle of the device can be extended to other gases $\left(\mathrm{NO}_{\mathrm{x}}, \mathrm{CH}_{4}, \mathrm{H}_{2} \mathrm{O} \ldots\right)$ displaying mid-IR absorption overlapping the broadband luminescence of Praseodymium ions but also to other rare-earth ions. Different mid-IR emission bands may be available in order to expand the operational range of this sensing device in terms of accessible wavelengths and target gases.

\section{ACKNOWLEDGMENT}

L.B., Y.D. and J.C. acknowledge financial support from Lannion Trégor Communauté, CD22, Region Bretagne and CPER SOPHIE. V.N. and P.N. are thankful to Czech Science Foundation (project No. 19-24516S).

\section{REFERENCES}

[1] M. Sieger and B. Mizaikoff, "Toward On-Chip Mid-Infrared Sensors", Anal. Chem., vol 88, no 11, pp 5562-5573, Apr. 2016, DOI: 10.1021/acs.analchem.5b04143

[2] P. Su, Z. Han, D. Kita, P. Becla, H. Lin, S. Deckoff-Jones, K. Richardson, L. C. Kimerling, J. Hu, and A. Agarwal, "Monolithic on-chip mid-IR methane gas sensor with waveguide-integrated detector", Appl. Phys. Lett., vol 114, no 5, pp 051103-1-051103-4, Feb. 2019, DOI: $10.1063 / 1.5053599$

[3] E. Baudet, A. Gutierrez-Arroyo, M. Baillieul, J. Charrier, P. Němec, L. Bodiou, J. Lemaitre, E. Rinnert, K. Michel, B. Bureau, J. L. Adam and V. Nazabal, "Development of an evanescent optical integrated sensor in the mid-infrared for detection of pollution in groundwater or seawater", $A d v$. Device Mater., vol 3, no 2, pp 23-29, Jun. 2017, DOI: 10.1080/20550308.2017.1338211

[4] Y.-C. Chang, P. Wägli, V. Paeder, A. Homsy, L. Hvozdara, P. van der Wal, J. Di Francesco, N. F. de Rooij and H. P. Herzig, "Cocaine detection by a mid-infrared waveguide integrated with a microfluidic chip ", Lab Chip, vol. 12, no 17, pp 3020-3023, Jun 2012, DOI: 10.1039/C2LC40601B

[5] R. Chandrasekar, Z. J. Lapin, A. S. Nichols, R. M. Braun, and A. W. Fountain III, "Photonic integrated circuits for Department of Defenserelevant chemical and biological sensing applications: state-of-the-art and future outlooks", Opt. Eng., vol 58, no 2, pp 020901-1-020901-11, Feb. 2019, DOI: 10.1117/1.OE.58.2.020901

[6] P. T. Lin, H.-Y. G. Lin, Z. Han, T. Jin, R. Millender,L. C. Kimerling, and A. Agarwal, "Label-Free Glucose Sensing Using Chip-Scale MidInfrared Integrated Photonics", Adv. Opt. Mater., vol 4, no 11, pp 1755-1759, Nov. 2016, DOI: 10.1002/adom.201600440

[7] M. Carras, G. Maisons, B. Simozrag, V. Trinite, M. Brun, G. Grand, P. Labeye, S. Nicoletti, "Monolithic tunable single source in the mid-IR for spectroscopy", Proc. SPIE 8631, Quantum Sensing and Nanophotonic Devices X, 863113 (4 February 2013); DOI: 10.1117/12.2009282

[8] C. Tsay, F. Toor, C. F. Gmachl, and C. B. Arnold, "Chalcogenide glass waveguides integrated with quantum cascade lasers for on-chip mid-IR photonic circuits", Opt. Lett., vol. 35, no. 20, pp. 3324-3326 (2010), DOI: 10.1364/OL.35.003324

[9] J. G Coutard, M. Brun, M. Fournier, O. Lartigue1, F. Fedeli, G. Maisons, J. M Fedeli, S. Nicoletti, M. Carras, and L. Durafourg, "Volume fabrication of Quantum Cascade Lasers on $200 \mathrm{~mm}-\mathrm{CMOS}$ pilot line", Sci. Rep., vol 10, 6185 (2020), DOI: 10.1038/s41598-020-63106-4

[10] V. Singh, P. T. Lin, N. Patel, H. Lin, L. Li, Y. Zou, F. Deng, C. Ni, J. Hu, J. Giammarco, A.P. Soliani, B. Zdyrko, I. Luzinov, S. Novak, J. Novak, P. Wachtel, S. Danto, J.D. Musgraves, K. Richardson, L.C.
Kimerling and A.M. Agarwal, "Mid-infrared materials and devices on a Si platform for optical sensing", Sci. Technol. Adv. Mater., vol. 15, no 1, pp 014603 (2014), DOI:10.1088/1468-6996/15/1/014603

[11] H. Lin, Z. Luo, T. Gu, L.C. Kimerling, K. Wada, A. Agarwal, and J. Hu, "Mid-infrared integrated photonics on silicon: a perspective", Nanophotonics, vol. 7, no 2 (2017), DOI: 10.1515/nanoph-2017-0085

[12] H. Podmore, A. Scott, P. Cheben, A. V. Velasco, J. H. Schmid, M Vachon, and R. Lee, "Demonstration of a compressive-sensing Fouriertransform on-chip spectrometer", Opt. Lett., vol. 42, no. 7, pp. 1440-1443, 2017, DOI: 10.1364/OL.42.001440

[13] M. Nedeljkovic, A. V. Velasco, A. Z. Khokhar, A. Delâge, P. Cheben, and G. Z. Mashanovich, "Mid-Infrared Silicon-on-Insulator Fourier-Transform

Spectrometer Chip", IEEE Photon. Technol. Lett., vol. 28, no. 4, pp 528-531 (2016), DOI: 10.1109/LPT.2015.2496729

[14] Q. Liu, J. M. Ramirez, V. Vakarin, X. Le Roux, C. Alonso-Ramos, J. Frigerio, A. Ballabio, E.Talamas Simola, D. Bouville, L. Vivien, G. Isella, and D. Marris-Morini, "Integrated broadband dual-polarization Ge-rich SiGe mid-infrared Fourier-Transform spectrometer", Opt. Lett., vol. 43, no. 20, pp. 5021-5024 (2018), DOI:10.1364/OL.43.005021

[15] M. Montesinos-Ballester, Q. Liu, V. Vakarin, J. M. Ramirez, C. Alonso-Ramos, X. Le Roux, J. Frigerio, A. Ballabio, E. Talamas, L. Vivien, G. Isella, and D. Marris-Morini "On-chip fourier-transform spectrometer based on spatial heterodyning tuned by thermooptic effect", Sci. Reports, vol. 9, p 14633 (2019), DOI: 10.1038/s41598-019-50947-x

[16] X. Nie, F. Ryckeboer, G. Roelkens, R. Baets, "CMOS-compatible broadband co-propagative stationary Fourier transform spectrometer integrated on a silicon nitride photonics platform”, Opt. Express vol. 25, no 8, pp A409-A418 (2017), DOI: 10.1364/OE.25.00A409

[17] D. Pohl, M. Reig Escalé, M. Madi, F. Kaufmann, P. Brotzer, A Sergeyev, B. Guldimann, P. Giaccari, E. Alberti, U. Meier and R. Grange "An integrated broadband spectrometer on thin-film lithium niobate", Nat Photonics, vol. 14, pp 24-29 (2020), DOI:10.1038/s41566-019-0529-9

[18] A. Malik, M. Muneeb, S. Pathak, Y. Shimura, J. Van Campenhout, R.Loo, and G. Roelkens, "Germanium-on-Silicon Mid-Infrared Arrayed Waveguide Grating Multiplexers”, IEEE Photon. Technol. Lett., vol. 25, no. 18, pp 1805-1808 (2013), DOI: 10.1109/LPT.2013.2276479

[19] A. Koshkinbayeva, P. Barritault, S. Ortiz, S. Boutami, M. Brun, J.M. Hartmann, P. Brianceau, O. Lartigue, F. Boulila, R.Orobtchouk, and P. Labeye, "Impact of Non-Central Input in $\mathrm{N} \times \mathrm{M}$ Mid-IR Arrayed Waveguide Gratings Integrated on Si”, IEEE Photon. Technol. Lett., vol. 28, no. 20, pp 2191-2194 (2016), DOI: 10.1109/LPT.2016.2587386

[20] P. Barritault, M. Brun, P. Labeye, J.-M. Hartmann, F. Boulila, M. Carras and S. Nicoletti, "Design, fabrication and characterization of an AWG at $4.5 \mu \mathrm{m}$ ", Opt. Express, vol. 23, no. 20, pp 26168- 26181 (2015), DOI 10.1364/OE.23.026168

[21] A. Malik, M. Muneeb, Y. Shimura, J. Van Campenhout, R. Loo, and G. Roelkens, "Germanium-on-silicon planar concave grating wavelength (de)multiplexers in the mid-infrared", Appl. Phys. Lett., vol 103, no. 16, p 161119 (2013), DOI: 10.1063/1.4826114

[22] E. Ryckeboer, A. Gassenq, M. Muneeb, N. Hattasan, S. Pathak, L. Cerutti, J.B. Rodriguez, E. Tournie, W. Bogaerts, R. Baets, and G. Roelkens, "Silicon-on-insulator spectrometers with integrated GaIn AsSb photodiodes for wide-band spectroscopy from 1510 to $2300 \mathrm{~nm}$ ", Opt. Express, vol. 21 no. 5, pp 6101-6108 (2013), DOI: 10.1364/OE.21.006101

[23] C. Gilles, L. J. Orbe, G. Carpintero, G. Maisons, and M. Carras, "Mid-infrared wavelength multiplexer in $\mathrm{InGaAs} / \mathrm{InP}$ waveguides using a Rowland circle grating", Opt. Express, vol. 23, no. 16, pp 20288-20196 (2015), DOI: 10.1364/OE.23.020288

[24] J. Xiao, X. Liu, and X. Sun, "Design of an ultracompact MMI wavelength demultiplexer in slot waveguide structures", Opt. Express, vol 15, no. 13, pp 8300-8308 (25 June 2007), DOI: 10.1364/OE.15.008300

[25] M. Rouifed, C. Littlejohns, G. Tina, H. Qiu, J. Penades, M. Nedeljkovic, Z. Zhang, C. Liu, D. Thomson, G. Mashanovich, G. Reed, and H. Wang, "Ultra-compact MMI-based beam splitter demultiplexer for the NIR/MIR wavelengths of $1.55 \mu \mathrm{m}$ and $2 \mu \mathrm{m}$," Opt. Express, vol. 25, no. 10, pp 10893-10900 (2017), DOI: 10.1364/OE.25.010893

[26] A. Sánchez-Postigo, J. Gonzalo Wangüemert-Pérez, R. Halir, A. Ortega-Moñux, C. A. Alonso-Ramos, Í. Molina-Fernández, J. Soler Penadés, M. Nedeljkovic, G. Z. Mashanovich, P. Cheben, "A subwavelength structured multimode interference coupler for the 3-4 micrometers midinfrared band", Proc. SPIE 9516, Integrated Optics: Physics and Simulations II, 95160L (1 May 2015), DOI: 10.1117/12.2179454

[27] Y. Hu, T. Li, D. J. Thomson, X. Chen, J. Soler Penades, A. Z. Khokhar, C. J. Mitchell, G. T. Reed, and G. Z. Mashanovich, "Mid-infrared wavelength division (de)multiplexer using an interleaved angled multimode interferometer on the silicon-on-insulator platform", Opt. Lett., vol. 39, no. 6, pp. 1406-1409 (2014), DOI:10.1364/OL.39.001406 
[28] Y. Wei, G. Li, Y. Hao, Y. Li, J. Yang, M. Wang, and X. Jiang, "Long-wave infrared $1 \times 2$ MMI based on air-gap beneath silicon rib waveguides", Opt. Express, vol. 19, no. 17, pp. 15803-15809, (2011), DOI: 10.1364/OE.19.015803

[29] H.-D. Kenchington Goldsmith, N. Cvetojevic, M. Ireland, and S. Madden, "Fabrication tolerant chalcogenide mid-infrared multimode interference coupler design with applications for Bracewell nulling interferometry", Opt. Express, vol. 25, no. 4, pp 3038-3051 (2017), DOI: 10.1364/OE.25.003038

[30] L. Bodiou, F. Starecki, J. Lemaitre, V. Nazabal, J.-L. Doualan, Emeline Baudet, R. Chahal, A. Gutierrez-Arroyo, Y. Dumeige, I. Hardy, A. Braud, R. Soulard, P. Camy, P. Němec, G. Palma, F. Prudenzano, J. Charrier, "Mid-infrared guided photoluminescence from integrated Pr3+-doped selenide ridge waveguides", Opt. Mater., vol. 75, pp. 109-115 (January 2018), DOI: $10.1016 /$ j.optmat.2017.10.001

[31] V. Nazabal, F. Starecki, J.-L. Doualan, P. Nemec, P. Camy, H. Lhermite, L. Bodiou, M.L. Anne, J. Charrier, J.L. Adam, "Luminescence at $2.8 \mathrm{~mm}$ : Er3+-doped chalcogenide micro-waveguide", Opt. Mater., vol. 58, pp. 390-397 (August 2016), DOI: 10.1016/j.optmat.2016.06.009

[32] J. A. Frantz, J. D. Myers, L. B. Shaw, J. S. Sanghera, "Integrated Optic Waveguides in Gallium Lanthanum Sulfide Glass for Mid-IR Applications", Proc. SPIE 10100, Optical Components and Materials XIV, 101000T (16 February 2017); doi: 10.1117/12.2253035

[33] F. Starecki, A. Braud, N. Abdellaoui, J. L. Doualan, C. BoussardPlédel, B. Bureau, P. Camy, and V. Nazabal, "7 to $8 \mu \mathrm{m}$ emission from Sm3+ doped selenide fibers", Opt. Express, vol 26, no 20, pp 26462-26469 (2018), DOI: $10.1364 / \mathrm{OE} .26 .026462$

[34] F. Starecki, G. Louvet, J. Ari, A. Braud, J. L. Doualan, R. Chahal, I. Hafienne, C. Boussard-Plédel, V. Nazabal, and P. Camy, "Dy3+ doped GaGeSbSe fiber long-wave infrared emission," J. Lumin., vol 218, p 116853 (2020), DOI: 10.1016/j.jlumin.2019.116853

[35] M. Shen, D. Furniss, M. Farries, D. Jayasuriya, Z. Tang, L. Sojka, S. Sujecki, T. M. Benson, and A. B. Seddon, "Experimental observation of gain in a resonantly pumped Pr3+-doped chalcogenide glass mid-infrared fibre amplifier notwithstanding the signal excited-state absorption", Sci. Rep., vol 9, p 11426 (2019). DOI: 10.1038/s41598-019-47432-w

[36] J. Ari, F. Starecki, C. Boussard-Plédel, Y. Ledemi, Y.Messaddeq, J. L. Doualan, A. Braud, B. Bureau, and V. Nazabal, "Co-doped Dy ${ }^{3+}$ and $\mathrm{Pr}^{3+} \mathrm{Ga}_{5} \mathrm{Ge}_{20} \mathrm{Sb}_{10} \mathrm{~S}_{65}$ fibers for mid-infrared broad emission," Opt. Lett., vol 43, no. 12, pp 2893-2896 (2018), DOI: 10.1364/OL.43.002893.

[37] I. A. Schultz, C. S. Goldenstein, R. Mitchell Spearrin, J. B. Jeffries, and R. K. Hanson, "Multispecies Midinfrared Absorption Measurements in a Hydrocarbon-Fueled Scramjet Combustor", J. Propul. Power, vol. 30, no. 6, pp 1595-1604 (November-December 2014), DOI: 10.2514/1.B35261

[38] L. B. Soldano and E. C. M. Pennings, "Optical multi-mode interference devices based on self-imaging: principles and applications", J. Lightwave Technol., vol. 13, no. 4, pp. 615-627, April 1995, DOI: 10.1109/50.372474.

[39] E. Baudet, A. Gutierrez-Arroyo, P. Němec, L. Bodiou, J. Lemaitre, J. Charrier, O. De Sagazan, H. Lhermitte, E. Rinnert, K. Michel, B. Bureau, V. Nazabal, "Selenide sputtered films development for MIR environmental sensor", Opt. Mater. Express, vol. 6, no. 8, pp. 2616-2627 (2016), DOI: 10.1364/OME.6.002616

[40] L. Bodiou, J. Lemaitre, G. Louvet, S. Normani, E. Baudet, F. Starecki, J. -L. Doualan, Y. Dumeige, I. Hardy, A. Braud, P. Camy, P. Nemec, G. Palma, F. Prudenzano,V. Nazabal, J. Charrier "Design of a midinfrared multispecies gas sensor based on $\mathrm{Pr} 3+$-doped chalcogenides waveguides," 2019 Photonics North (PN), Quebec City, QC, Canada, 2019, pp. 1-1. DOI: 10.1109/PN.2019.8819593

[41] P. Nemec, M. Olivier, E. Baudet, A. Kalendova, P. Benda, and V. Nazabal, "Optical Properties of $\left(\mathrm{GeSe}_{2}\right)_{100-\mathrm{x}}\left(\mathrm{Sb}_{2} \mathrm{Se}_{3}\right)_{\mathrm{x}}$ Glasses in Near- and Middle-Infrared Spectral Regions", Mater. Res. Bull., vol. 51, pp 176-179 (March 2014), DOI: 10.1016/j.materresbull.2013.11.050

[42] J. Kischkat, S. Peters, B. Gruska, M. Semtsiv, M. Chashnikova, M. Klinkmüller, O. Fedosenko, S. Machulik, A. Aleksandrova, G. Monastyrskyi, Y. Flores, and W. T. Masselink, "Mid-infrared optical properties of thin films of aluminum oxide, titanium dioxide, silicon dioxide, aluminum nitride, and silicon nitride", Appl. Opt., vol. 51, no. 28 pp. 67896798 (2012), DOI: 10.1364/AO.51.006789

[43] Y. Wang, S. Qi, Z. Yang, R.Wang, A. Yang, P. Lucas, "Composition dependences of refractive index and thermo-optic coefficient in Ge-As-Se chalcogenide glasses", J. Non-Cryst. Solids, vol. 459, pp 88-93 (1 March 2017), DOI: 10.1016/j.jnoncrysol.2017.01.004

[44] Y. Fang, D. Furniss, D. Jayasuriya, H. Parnell, Z. Tang, A.B. Seddon, and T.M. Benson, "Determining the continuous thermo-optic coefficients of chalcogenide glass thin films in the MIR region using FTIR transmission spectra", Opt. Express, vol. 27, no. 16, pp. 22275-22288 (2019) DOI: $10.1364 / O E .27 .022275$
[45] W. Bogaerts and L. Chrostowski, "Silicon Photonics Circuit Design: Methods, Tools and Challenges", Laser Photonics Rev., vol 12, no 4, p 1700237(2018), DOI: 10.1002/lpor.201700237

[46] D. J. Thomson, Y. Hu, G. T. Reed, and Jean-Marc Fedeli, "Low Loss MMI Couplers for High Performance MZI Modulators", IEEE Photon. Technol. Lett., vol. 22, no. 20, pp 1485-1487, Oct. 2010, DOI: 10.1109/LPT.2010.

[47] M. T. Hill, X. J. M. Leijtens, G. D. Khoe, and M. K. Smit "Optimizing Imbalance and Loss in 223 - $\mathrm{dB}$ Multimode Interference Couplers via Access Waveguide Width", J. Lightwave Technol., vol. 21, no. 10, pp. 2305-2313, Oct. 2005, DOI: 10.1109/JLT.2003.818164

Loïc Bodiou received his $\mathrm{PhD}$ from the University of Caen (France) in 2007. This work was focused on the luminescence of rare earth ions in nitride semiconductors. He was appointed as associate professor at University of Rennes 1 in 2009. His current research interests are related to the design, technological processing and optical characterizations of photonic integrated circuits based on (rare earth-doped) chalcogenides for optical signal processing, IR and mid-IR light sources or sensing applications.

Yannick Dumeige graduated from the Ecole Supérieure d'Optique, Orsay, France, in 1999 and received the Ph.D degree from the University of Paris XI, Orsay in 2002. In 2002 he spent one year at Laboratoire de Photonique Quantique et Moléculaire and Ecole Normale Supérieure de Cachan (France) as a postdoctoral research and teaching assistant. In 2003 he joined the University of Rennes 1 as an associate professor. In 2013, he was nominated Junior Member of the Institut Universitaire de France. His current research interests are integrated nonlinear optics, optical micro-cavities and sensors.

Simone Normani Simone Normani obtained his B.Sc. in physics from the University of Trento in 2011, and went on to receive a M.Sc. in experimental physics at the same University in 2013, with specialization in disordered systems and nanomaterials, in collaboration with the CMSFO group at the CNR-IFN laboratory in Trento. He achieved his Ph.D. title in 2017 from the University of Caen, France, and held a postdoc position as specialist in inorganic materials at the Faculty of Chemical Technology of the University of Pardubice, Czech Republic, from 2018 to 2020 working on rare earth-doped chalcogenide glasses for MIR applications. $\mathrm{He}$ is now working as postdoc at the Center for Nano Science and Technology in Milan, with an interest in multilayer devices for bacterial sensing applications.

Geoffrey Louvet obtained a Bachelor's degree in Chemistry and in 2017 a Master's degree in Solid State and Materials Chemistry from the University of Rennes 1 (France). He is currently pursuing a $\mathrm{PhD}$ in Chemistry between the ISCR at the University of Rennes 1 and the COPL at Laval University, (Québec, Canada) under the cosupervision of Dr. V. Nazabal and Prof. Y. Messaddeq. He specializes in the study of the fluorescence of lanthanide ions in chalcogenide glasses, glass target preparation for sputtering and e-beam evaporation, and the anodic oxide glass-silicon bonding.

Petr Němec received his $\mathrm{PhD}$ degree in Chemistry and Technology of Inorganic Materials from University of Pardubice (2002). Since 2006, he worked as Associate Professor at Faculty of Chemical Technology, University of Pardubice. He became full Professor in 2015. He works in the 
field of inorganic glasses and amorphous thin films focusing of the thin films.

Virginie Nazabal, she received the B.S. and M.S. degrees in chemistry in 1996 from Ecole Normale Supérieure, University of Paris VI. She got her PhD degree in Solid State Chemistry and Material Sciences from the University of Bordeaux (France) in 1999. She joined the NIMS (Tsukuba, Japan) as JSPS post-doctoral fellowship in 2000. She has belonged to the CNRS as a permanent Researcher since 2001 and has been a Senior Researcher at CNRS since 2015. Her research activity is dedicated to vitreous materials for optics at the Institute of Chemical Sciences of the University of Rennes (France). She is currently exploring the potential offered by glass, thin films and fibers for photonic devices such as infrared optical sensors. She is co-author of 3 chapters of book and more than 175 peer-reviewed scientific articles. She received in 2010 a bronze medal of CNRS and a PollutecAdeme Award in 2011 for Innovative Techniques for the Environment.

Joël Charrier received the $\mathrm{Ph} . \mathrm{D}$. degree from the University of Rennes 1, France, in 2000. His dissertation was devoted to the study of light propagation in silicon-based nanostructured waveguides. Since 2000, he has been with the FOTON Institute as assistant-professor at University of Rennes 1 . He is interested in photonic integrated circuits for optical communication and sensing applications. He is currently the head of the Guided Optics and Sensors research group (OGC-Optique Guidée et Capteurs) of FOTON Institute. 


\begin{abstract}
A $1 \times 2$ multimode interferometer beam splitter based on mid-infrared emitting chalcogenides waveguides is designed. This device multiplexes mid-infrared light in two channels whose respective passbands overlap either $\mathrm{CO}_{2}$ or $\mathrm{CO}$ absorption bands, respectively between $4.20-4.32 \mu \mathrm{m}$ and $4.50-$ $4.86 \mu \mathrm{m}$. The proposed device offers a low-cost solution for monolithic combination of broadband on-chip mid-infrared light emission with dispersive spectroscopic element devoted to mid-IR multigas sensing applications. Based on restrictive interference mechanism in a $1 \times 2$ multimode interferometer, the multimode section dimensions (width and length) are engineered to increase the imbalance between the two ports for the two passbands and consequently to increase the output contrast ratio. Tolerances to variations from the optimum device design resulting from processing conditions (materials fabrication and sputtering, photolithography and dry etching steps) are assessed. In particular, the $1 \times 2$ multimode interferometer diplexer spectral transmission is investigated as a function of deposited film refractive index and multimode section dimensions (width and length) deviation from designed values. Input and output ports tapering is introduced to reduce the device insertion loss.
\end{abstract}

Index Terms-Amorphous materials, Chalcogenides thin films, Environmental monitoring, Infrared spectroscopy, Integrated circuit design, Luminescent devices, Mid-Infrared sensors, Optical strip waveguides components, Photonic Integrated Circuits, And Praseodymium

\section{INTRODUCTION}

MID-INFRARED (mid-IR) integrated sensing of liquids and gases [1] has found applications as diverse as environmental monitoring and pollutant detection (smoke and greenhouse gases detection [2], emerging water pollutant identification [3]), military and homeland security (detection of drugs [4] and hazardous materials [5]) but also industrial and healthcare (food processing industry, pharmaceutical and medical products identification [6]).

Different bulk optical components (modulator, splitter or polarizer) have been transposed in photonic integrated circuits (PIC) thanks to technical advancements witnessed in

L. Bodiou, Y. Dumeige and J. Charrier are with Univ Rennes, CNRS, Institut FOTON - UMR 6082, F-22305 Lannion, France (e-mail: Loic.Bodiou@univ-rennes1.fr, Y Yannick.Dumeige@univ-rennes1.fr, Joel.Charrier@univ-rennes1.fr),

G. Louvet and V. Nazabal are with Univ Rennes, CNRS, ISCR (Institut des Sciences Chimiques de Rennes) - UMR 6226, F-35000 Rennes, France (e-mail: Geoffrey.Louvet@univ-rennes1.fr, Virginie.Nazabal@univrennes1.fr)

S. Normani and P. Němec are with the Department of Graphic Arts and Photophysics, Faculty of Chemical Technology, University of Pardubice, 53210, Pardubice, Czech Republic (e-mail: Simone.Normani@iit.it, Petr.Nemec@upce.cz). the last two decades. In particular, recent advancements have associated both the mid-IR light source (Quantum Cascade Lasers or QCL) and waveguides [7]-[9] or transducer and detector [2] on the same chip. However, monolithic integration of a complete sensing platform combining a broadband mid-IR light source, transducer and detector is still challenging [10],[11].

To improve detection capability of photonic integrated circuits, numerous works have also targeted the miniaturization of optical spectrometers. Various configurations of Fourier Transform spectrometers, namely spatial heterodyne spectrometers (SHS) and stationary-wave integrated Fourier-transform spectrometry (SWIFTS) systems have been reported using different materials platforms including silicon [12],[13], Ge rich SiGe [14],[15], silicon nitride [16] or lithium niobate [17]. Other spectroscopic or (de)multiplexing systems based on dispersive devices such as array waveguide gratings (AWG) [18]-[20] planar concave gratings (also known as echelle grating) [21]-[23] have also been demonstrated to operate in mid-IR spectral domain. Wavelength division (de)multiplexer based on multimode interferometers (MMI) have been proposed to split telecommunication wavelengths (1.3/1.55 $\mu \mathrm{m}$ [24] and 1.55/2 $\mu \mathrm{m}$ multiplexers [25]). MMI devices operating at mid-IR wavelengths have also been implemented using silicon on insulator [26],[27] suspended silicon [28] or chalcogenides [29] platforms.

As many gases, such as $\mathrm{CH}_{4}, \mathrm{CO}_{2}, \mathrm{CO}$ or $\mathrm{NO}_{\mathrm{x}}$ have strong absorption features in the mid-IR, environmental monitoring will benefit from the development of a spectroscopic sensing platform incorporating a broadband light source operating in the 3-5 $\mu \mathrm{m}$ spectral region. Rare-earth doped chalcogenides have been shown to display broadband mid-IR luminescence in integrated waveguides [30]-[32] and fibers [33]-[36] enabling remote detection of $\mathrm{CH}_{4}$ and $\mathrm{CO}_{2}$ for field operations or in situ monitoring in microfluidic system [2][4]. Therefore, monolithic association of a broadband mid-IR light source based on rare-earth doped chalcogenides with an integrated spectroscopic system made from the same materials could help the development of multi-analyte sensor systems on a chip that are expected to have a positive impact on a myriad of applications. In particular, an integrated dualgas sensor for the simultaneous detection of $\mathrm{CO}_{2}$ and $\mathrm{CO}$ gases could be advantageously used, for example, in the aeronautic industry [37]. Indeed, environmental regulations become more stringent and require the monitoring of aircraft emission to reduce greenhouse gas emission due to incomplete kerosene combustion.

In this paper, we report the design of a $1 \times 2 \mathrm{MMI}$ 
multiplexer operating in the mid-IR spectral region based on chalcogenides waveguides to develop a multispecies gas sensor. The MMI dimensions are assessed to enable the multiplexing of mid-IR broadband emission from $\mathrm{Pr}^{3+}$-doped selenides to develop a dual-gas sensor allowing simultaneous detection of $\mathrm{CO}$ and $\mathrm{CO}_{2}$ gases. The MMI multimode section dimensions are engineered to enlarge the operation bandwidth and to diplex mid-IR light on two spectral windows overlapping $\mathrm{CO}$ and $\mathrm{CO}_{2}$ absorption bands (Fig. 1), each of them coming through one of the two MMI output channels. The design robustness is then assessed over different parameters such as refractive index change or multimode section width and length variation. Finally, tapered input and output ports are introduced to further relax fabrication tolerances and to reduce device insertion optical losses.

\section{DEVICE DESIGN}

\section{A. Device operating principles}

In a conventional $1 \times 2 \mathrm{MMI}$, a single-mode input port is laterally centered in relation to the multimode section width $\left(\mathrm{w}_{\text {MMI }}\right)$. Multiple optical modes are thus excited by the optical mode arising from the single-mode input. Constructive interferences between these modes give rise to single or multiple replica of the input mode in the multimode section at periodic positions along the propagation direction in a wellknown self-imaging effect [38].

Under restricted interferences regime, the input and output ports are shifted by $\pm \mathrm{w}_{\mathrm{MMI}} / 6$ with respect to the center of the multimode region width (Fig. 2). In such a case, only certain optical modes will be excited in the multimode section of the MMI. Therefore, solely direct or mirrored image of the input field will be observed along the propagation direction in the multimode section. These images will, respectively, occur at even and odd integers of the so-called beat length $L_{\pi}^{\lambda}$ defined as:

$$
L_{\pi}^{\lambda}=\frac{\pi}{\beta_{0}-\beta_{1}} \approx \frac{4 \cdot n_{e f f, 0} \cdot W_{\text {eff }}^{2}}{3 \cdot \lambda}
$$

where $\beta_{0}$ and $\beta_{1}$ are the propagation constants for the two lowest order modes, $\mathrm{n}_{\text {eff, }, 0}$ is the effective refractive index of the MMI multimode region fundamental mode, $\lambda$ is the wavelength and $\mathrm{W}_{\text {eff }}$ is the effective multimode section width which can be approximated to $\mathrm{W}_{\mathrm{MMI}}$ for high contrast waveguides [38].

Based on the restricted interference mechanism in its multimode section, it is thus possible to use a MMI to separate two different wavelengths $\lambda_{1}$ and $\lambda_{2}$ incoming from the same input port into two output channels corresponding to port 1 and port 2 by forming a direct image at a given wavelength and a mirrored image at the other. To do so, the width and length of the MMI multimode section must be chosen to satisfy the following conditions [24],[25]:

$$
L_{M M I}=p \cdot L_{\pi}^{\lambda_{1}}=(p+q) \cdot L_{\pi}^{\lambda_{2}}
$$

where $\mathrm{p}$ is a positive integer, $\mathrm{q}$ is an odd integer and $L_{\pi}^{\lambda_{i}}$ is the beat length at the wavelength $\lambda_{\mathrm{i}}$ defined in (1).

In the proposed device, the MMI multimode section is designed so that the wavelengths corresponding to the absorption bands of $\mathrm{CO}_{2}$ (black shaded region in Fig. 1) will exit the MMI multimode section through one of the output ports whereas wavelengths corresponding to the absorption bands of $\mathrm{CO}$ (red shaded region in Fig. 1) will come out through the other output port.

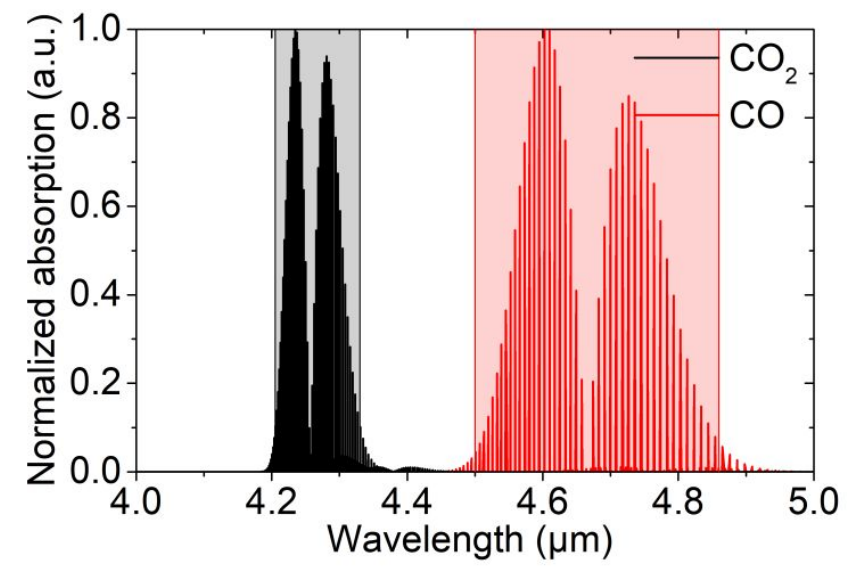

Fig. 1. Normalized absorption bands of carbon monoxide (CO) and carbon dioxide $\left(\mathrm{CO}_{2}\right)$. The two bands to multiplex are superimposed to these spectra.

\section{B. Description of the MMI structure}

The materials platform used to design the MMI follows from [30] where Praseodymium-doped selenides films $\left(\mathrm{Ga}_{5} \mathrm{Ge}_{20} \mathrm{Sb}_{10} \mathrm{Se}_{65}: 5000 \mathrm{ppm} \mathrm{Pr}^{3+}\right)$ are deposited from glass targets prepared by means of conventional melt and quenching method [39] by radio frequency (RF) magnetron sputtering on thermally oxidized $\left(4-\mu \mathrm{m}\right.$ thick $\left.\mathrm{SiO}_{2}\right) 2$ " silicon wafer. Subsequent ridge waveguides fabrication was achieved through a classical $i$-line photolithographic process followed by a fluorine-based inductively coupled plasmareactive ion etching (ICP-RIE) process. Single-mode waveguiding and photoluminescence overlapping $\mathrm{CO}$ and $\mathrm{CO}_{2}$ absorption in the 4 to $5 \mu \mathrm{m}$ spectral range (Fig. 1) was previously observed [30],[40]. Fibers of the same glass composition but codoped with $\mathrm{Dy}^{3+}$ and $\mathrm{Pr}^{3+}$ enabled simultaneous detection of $\mathrm{CO}_{2}$ and $\mathrm{CH}_{4}$ [36]. The linear refractive indices used in the simulations for chalcogenide and $\mathrm{SiO}_{2}$ thin films were, respectively, obtained from the analysis of variable angle spectroscopic ellipsometry data [41] and from [42].

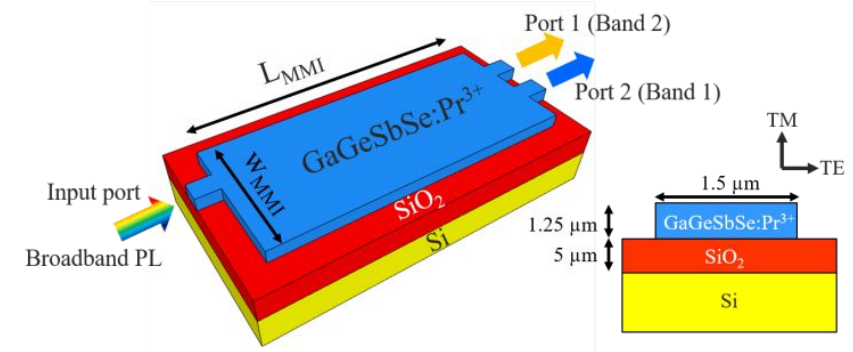

Fig. 2. Schematic representation of the multiplexing MMI structure based on GaGeSbSe:Pr ${ }^{3+}$. The cross-section of the input port is displayed on the right.

\section{MMI dimensions optimization}

Simulations were performed using the FIMMPROP propagation module integrated with FIMMWAVE software and based on the eigenmode expansion (EME) method. These computations were undertaken with a real semi-vectorial finite difference method (FDM) mode solver in TE polarization and used a $50 \mathrm{~nm} \times 50 \mathrm{~nm}$ transverse grid size.

The optimization of the MMI multimode section dimensions is aimed at obtaining a direct image for wavelengths used for sensing the first gas (band i) and a 
mirrored image for wavelengths at which the second gas absorbs (band $\mathrm{j}$ ). In the simulations, the fundamental TE mode of the input waveguide corresponding to the crosssection displayed in Fig. 2 was launched at the MMI entrance. The transmitted power at both output ports was then monitored as a function of MMI multimode section width $\left(\mathrm{w}_{\mathrm{MMI}}\right)$ and length $\left(\mathrm{L}_{\mathrm{MMI}}\right)$ for different wavelengths corresponding to the absorption wavelengths of $\mathrm{CO}$ and $\mathrm{CO}_{2}$ gases. The MMI width was scanned between 10 and $50 \mu \mathrm{m}$ whereas MMI lengths ranged from 10 to $2500 \mu \mathrm{m}$ (Fig. 3).

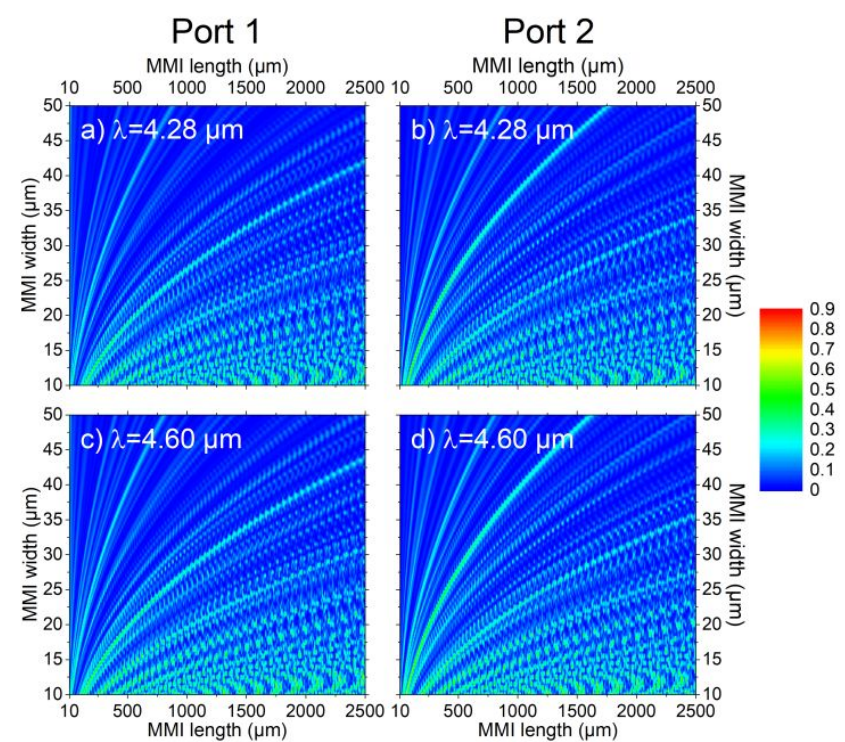

Fig. 3. Power transmission for the two output ports as a function of MMI multimode section width ( $\left.\mathrm{w}_{\mathrm{MMI}}\right)$ and length $\left(\mathrm{L}_{\mathrm{MMI}}\right)$ for two wavelengths: $\left.\mathrm{a}\right)$, b) $4.28 \mu \mathrm{m}$ and c), d) $4.6 \mu \mathrm{m}$.

Simulation results obtained for wavelengths equal to $\lambda=4.28 \mu \mathrm{m}$ and $\lambda=4.6 \mu \mathrm{m}$ corresponding, respectively, to the wavelengths of maximum absorption from $\mathrm{CO}_{2}$ and $\mathrm{CO}$ gases are displayed in Fig. 3. From these different figures, it can be observed that, for some $\mathrm{w}_{\mathrm{MMI}}$ and $\mathrm{L}_{\mathrm{MMI}}$, the imbalance between both ports can be high for two different wavelengths. However, in opposition to previously reported MMI-based multiplexers [24],[25], in this device, rather than single wavelengths, broad bands (150 to $350 \mathrm{~nm}$ ) have to be separated. MMI transmission on both output ports was thus simulated for different wavelengths separated by $15 \mathrm{~nm}$. Band 1 (corresponding to the black shaded area in Fig. 1) was sampled with 8 different wavelengths whereas 23 wavelengths were used for the broader second band (red shaded area in Fig. 1). The mean intensity on output ports 1 ( $\mathrm{I}_{\text {Band } 1 \text { or 2, Port 1 }}$ ) and 2 ( $\mathrm{I}_{\text {Band } 1 \text { or 2, Port } 2) \text { were then computed over }}$ Bands 1 and 2 for each ( $\mathrm{w}_{\mathrm{MMI}}, \mathrm{L}_{\mathrm{MMI}}$ ) couple using the following expressions:

$$
\begin{aligned}
I_{\text {Band } 1, \text { Port } j}=\frac{\sum_{\lambda_{i}=1}^{8} I_{\text {Port } j}^{\lambda_{i}}}{8} & \frac{\sum_{\lambda_{i}=1}^{23} I_{\text {Port } j}^{\lambda_{i}}}{23}
\end{aligned}
$$

where $\mathrm{j}=1,2$ and corresponds to output port number (Fig. 2). The sum does not contain the same number of wavelength terms for Band 1 and Band 2 because the spacing between simulated wavelengths was kept constant even if the absorption bands have different spectral widths. No correction factors were applied to the terms of this calculation as flat-top passbands were considered to anticipate versatile device operation in terms of gas pressure or temperature resulting in absorption spectra change.

As there is no preferential output port for sensing any of the gases, the two output ports can be treated similarly. For each ( $\left.\mathrm{w}_{\mathrm{MMI}}, \mathrm{L}_{\mathrm{MMI}}\right)$ couple, calculations were then performed to evaluate two different ratios defined as:

$$
\begin{aligned}
S_{A} & =\frac{I_{\text {Band 1, Port 1 }} \times I_{\text {Band 2, }} \text { Port 2 }}{I_{\text {Band 1, Port } 2} \times I_{\text {Band 2, }} \text { Port 1 }} \\
S_{B} & =\frac{I_{\text {Band 1, Port } 2} \times I_{\text {Band 2, Port 1 }}}{I_{\text {Band 1, Port 1 }} \times I_{\text {Band 2, Port } 2}}
\end{aligned}
$$

Maximization of $\mathrm{S}_{\mathrm{A}}$ and $\mathrm{S}_{\mathrm{B}}$ will result in the most efficient multiplexing of broadband light source over the two channels. In scheme $A$, for which $S_{A}$ is maximal, the wavelengths devoted to $\mathrm{CO}_{2}$ sensing (Band 1) would come out through port 1 (direct image) and wavelengths useful to detect $\mathrm{CO}$ (Band 2) would be transmitted through port 2 (mirror image). In scheme $B$, for which $S_{B}$ is maximal, the application of the two channels would be opposite.

Some ( $\mathrm{w}_{\mathrm{MMI}}, \mathrm{L}_{\mathrm{MMI}}$ ) couples enable the transmission of only a very small fraction of the incident light on one of the output ports. In that case, $\mathrm{S}_{\mathrm{A}}$ and $\mathrm{S}_{\mathrm{B}}$ can reach high values independently of the corresponding transmitted intensity through the other port. To avoid this numerical artifact, a minimum mean transmitted intensity of $35 \%$ for the through port was added as a supplementary condition to the evaluation of $\mathrm{S}_{\mathrm{A}}$ and $\mathrm{S}_{\mathrm{B}}$.

With these conditions, optimized dimensions of the MMI multimode region were found to be $\mathrm{w}_{\mathrm{MMI}}=10 \mu \mathrm{m}$ and $\mathrm{L}_{\mathrm{MMI}}=519 \mu \mathrm{m}$ (TABLE I).

TABLE I

LIST OF PARAMETERS OF OPTIMIZED MM

\begin{tabular}{lc}
\hline \multicolumn{1}{c}{ Parameter } & Value \\
& \\
\hline Waveguide height $h$ & $1.25 \mu \mathrm{m}$ \\
Input port width $w$ & $1.5 \mu \mathrm{m}$ \\
Output ports width $w$ & $1.5 \mu \mathrm{m}$ \\
Multimode section width $w_{M M I}$ & $10 \mu \mathrm{m}$ \\
Multimode section length $L_{M M I}$ & $519 \mu \mathrm{m}$ \\
Band 1 & $4.20-4.32 \mu \mathrm{m}$ \\
Band 2 & $4.50-4.86 \mu \mathrm{m}$ \\
\hline \hline
\end{tabular}

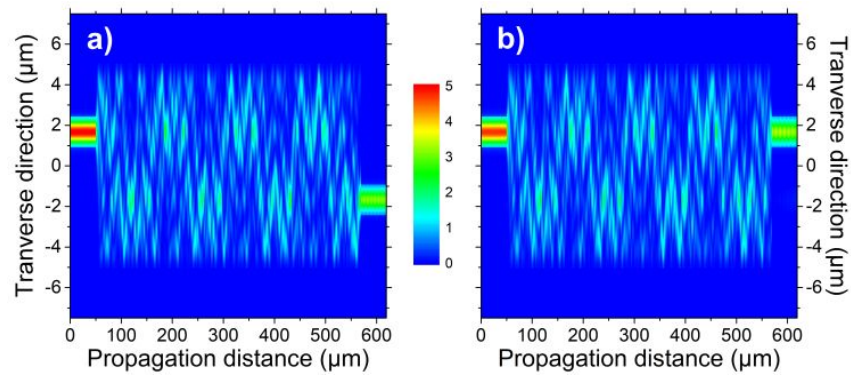

Fig. 4. Simulation of the power transmission for the MMI with optimized dimensions at a) $4.3 \mu \mathrm{m}$ and b) $4.6 \mu \mathrm{m}$.

Fig. 4 shows the power transmission through the optimized MMI for wavelengths of $4.28 \mu \mathrm{m}$ and $4.6 \mu \mathrm{m}$ that are close to the absorption maxima of $\mathrm{CO}_{2}$ and $\mathrm{CO}$, respectively. From this Fig. 4, it can be seen that mid-IR light can efficiently be multiplexed over the two different output ports using a MMI operated in the restricted interferences regime. 


\section{III.ROBUSTNESS TO FABRICATION TOLERANCES}

As the device performances must not be altered by fabrication imperfections, it is important that tolerances are relaxed regarding the device fabrication and processing. These relaxed tolerances concern the reproducibility and the thermal variation (thermo-optic coefficient or $\mathrm{dn} / \mathrm{dT}$ ) of the refractive index of the sputtered $\mathrm{Pr}^{3+}$-doped chalcogenides thin films but also the geometrical dimensions control during technological processing (photolithography and etching).

\section{A. Refractive index change}

Refractive index changes of the sputtered $\operatorname{Pr}^{3+}: \mathrm{GaGeSbSe}$ films can originate from various reasons. The most obvious is a variation related to the operating temperature, which will depend on the $\mathrm{dn} / \mathrm{dT}$ coefficient not well-known in case of chalcogenide thin films. Considering values of 76 and $91 \times$ $10^{-6} \mathrm{~K}^{-1}$ (respectively at wavelength of 3.4 and $10.6 \mu \mathrm{m}$ ) for the thermo-optic coefficient of $\mathrm{Ge}_{28} \mathrm{Sb}_{12} \mathrm{Se}_{60}$ glass and its thermal expansion coefficient of $14 \times 10^{-6} \mathrm{~K}^{-1}$, the $\mathrm{dn} / \mathrm{dT}$ value of the $\mathrm{Ga}_{5} \mathrm{Ge}_{20} \mathrm{Sb}_{10} \mathrm{Se}_{65}$ glass composition, which displays a thermal expansion coefficient of $16 \times 10^{-6} \mathrm{~K}^{-1}$, might be slightly lower than $91 \times 10^{-6} \pm 10 \times 10^{-6} \mathrm{~K}^{-1}$ [43],[44]. If uniformity in terms of thickness and refractive index is observed over a 2" sample, there could be a \pm 0.01 refractive index deviation from one film to another, due to the possible slight different composition of the target from batch to batch or wear of the target during deposition. To evaluate the impact of this effect, the wavelength dependence of the transmission through the two output ports of the optimized MMI structure (TABLE I) was simulated for different refractive index changes. Results from these simulations are displayed in Fig. 5.

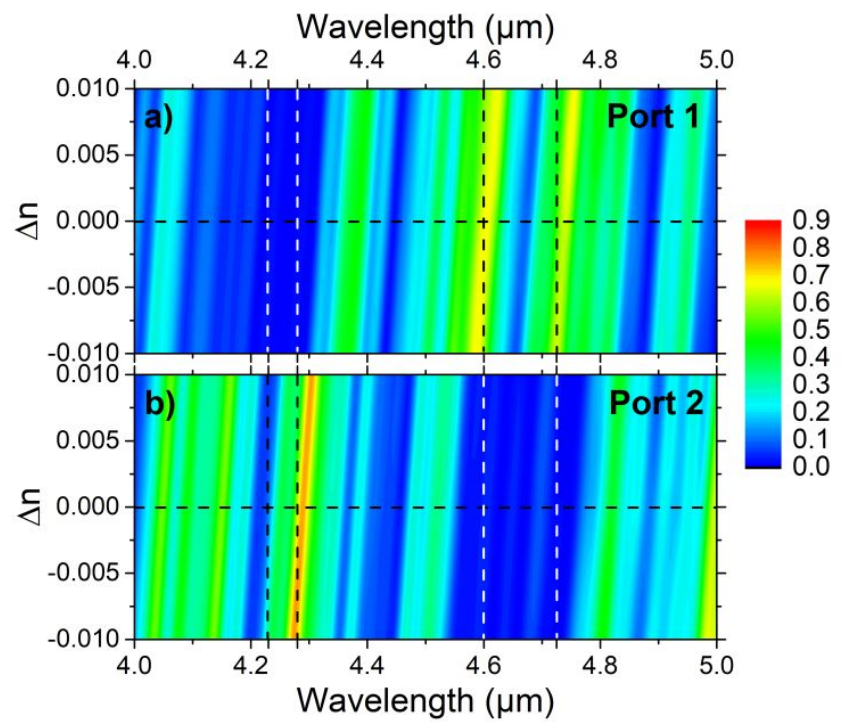

Fig. 5. Wavelength dependence of a) Port 1 and b) Port 2 transmission as a function of chalcogenide film refractive index variations $(\Delta n)$ for optimized MMI multimode section dimensions. Vertical dashed lines correspond to absorption maxima of $\mathrm{CO}_{2}$ and $\mathrm{CO}$.

Horizontal dashed lines in Fig. 5 correspond to the transmission through both output ports, respectively for Port 1 in Fig. 5a) and Port 2 in Fig. 5b), when the conventional

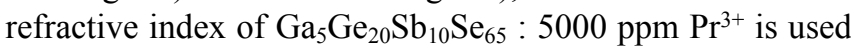
in the simulations. Dashed vertical lines in Fig. 5 correspond to the wavelengths of maximum absorption from $\mathrm{CO}$ and CO2 (Fig. 1).

From this Fig. 5, it can be confirmed that the optimized MMI dimensions enable an efficient multiplexing of $\mathrm{CO}$ - and $\mathrm{CO}_{2}$ related absorption bands through the two output ports. Indeed, a maximum of transmission over Band 1 or 2 on one port correspond a minimum of transmission of the same Band on the other port. Nonetheless, it can be noticed, in Fig. 5, that $\mathrm{CO}_{2}$ second absorption band maximum is found at $\lambda=4.28 \mu \mathrm{m}$ whereas the transmission maximum through Port 2 for MMI multimode section optimized dimensions is slightly shifted by $10 \mathrm{~nm}$ at $\lambda=4.29 \mu \mathrm{m}$. The transmission through Port 2 of the optimized device (horizontal dashed line in Fig. 5) is about $65 \%$ at $\lambda=4.28 \mu \mathrm{m}$ and reaches $76 \%$ at $\lambda=4.29 \mu \mathrm{m}$. However, to ensure device operation in different environments in terms of gas pressure or temperature which will change gas absorption spectral signature, Bands have to be considered as flat-top pass-bands and consequently their respective bandwidths must be taken into account. This is the reason why MMI structure optimization procedure, through the maximization of $\mathrm{S}_{\mathrm{A}, \mathrm{B}}$ (defined in Equations (5)-(6)), was targeting maximum transmission over a band whose bandwidth is more than $100 \mathrm{~nm}$ rather than at a specific wavelength.

From Fig. 5, it is also observed that the transmission band and bandwidth of any port are hardly affected by a moderate refractive index change up to \pm 0.01 .

\section{B. Multimode section width and length}

The effect of processing imperfections must also be assessed. Indeed, lithographic (photoresist aging, thickness or exposure variation) and etching (plasma density) steps can strongly influence the geometric parameters of processed MMI. Evaluation of the designed MMI device variability on different levels scales (intra-die, die-to-die and wafer-towafer) must therefore be performed [45]. To this end, impact of MMI multimode section length and width variations were computed (Fig. 6 and Fig. 7)

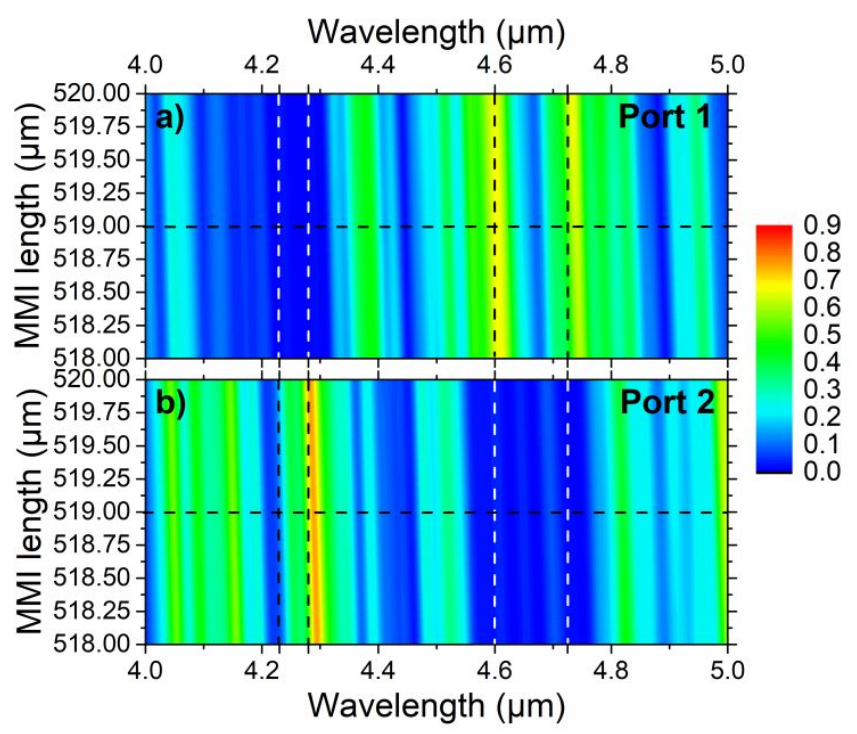

Fig. 6. Wavelength dependence of a) Port 1 and b) Port 2 transmission as a function of MMI multimode section length $\left(\mathrm{L}_{\mathrm{MMI}}\right)$.

From Fig. 6, it can be seen that the global shape of the color 
maps yields almost vertical lines, which means that the wavelength dependence of the transmission on both ports is rather similar for each MMI multimode section length $\mathrm{L}_{\mathrm{MMI}}$ simulated. Consequently, important variations of the MMI multimode section length hardly influences the wavelength response of the transmission. As it can be envisioned that processed devices will not suffer from such large $( \pm 1 \mu \mathrm{m})$ length variations, this parameter change is expected not to strongly affect the device performance.

The color maps presented in Fig. 7 display a very different behavior compared to those observed in Fig. 5 and Fig. 6 where vertical shapes could be seen. For example, in Fig. 7, a $200 \mathrm{~nm}$ change of $\mathrm{w}_{\mathrm{MMI}}$ (from $10 \mu \mathrm{m}$ to $9.8 \mu \mathrm{m}$ ) decreases the transmission at $4.29 \mu \mathrm{m}$ and at $4.6 \mu \mathrm{m}$, respectively through Port 2 and Port 1 , from $\sim 80 \%$ to less than $10 \%$. This spectral dependence of the multiplexing on MMI multimode section width can be explained by the corresponding effective refractive index change, which strongly impacts the beat length and thus the transmission.

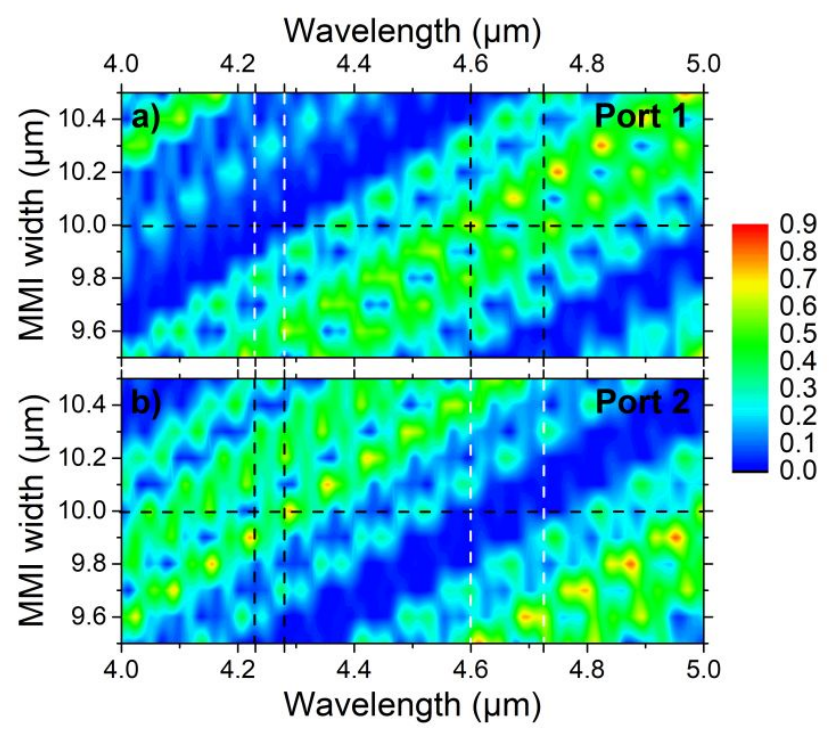

Fig. 7. Wavelength dependence of a) Port 1 and b) Port 2 transmission as a function of MMI multimode section width ( $\mathrm{w}_{\mathrm{MMI}}$ ) with straight input and output ports (ports width $=1.5 \mu \mathrm{m}$ ).

\section{Tapered input and output ports}

Tapered port implementation was demonstrated to advantageously enable device insertion loss reduction and relax the impact of fabrication errors on MMI transmission [46],[47]. To enhance device transmission and to mitigate the detrimental effect of $\mathrm{w}_{\mathrm{MMI}}$ change on spectral transmission, tapered input and output ports were then introduced in the simulations. The designed taper is identical on all ports (input and output) and consists of a $25-\mu \mathrm{m}$ long linear tapering of the port waveguide width. Simulation results are presented in Fig. 8.

The taper width was scanned between $\mathrm{w}_{\text {taper }}=1.5 \mu \mathrm{m}$ to $\mathrm{w}_{\text {taper }}=3.25 \mu \mathrm{m}$. The former width corresponds to the single mode straight waveguides width whereas the latter is approximately equal to half of the distance between output ports. From Fig. 8, it can be noticed that the transmission increases globally as the taper width is enlarged. For large widths (above $\mathrm{w}_{\text {taper }}=3 \mu \mathrm{m}$ ), the pass bands widen and tend to shift relative to the absorption maxima of $\mathrm{CO}_{2}$ and $\mathrm{CO}$ (represented by the vertical dashed lines). An optimum taper width of $3 \mu \mathrm{m}$ is therefore inferred from this Fig. 8. These results are in accordance with previous reports stating that the optimum taper width with regards to transmission is $3 / 10^{\text {th }}$ of the MMI multimode width [29].

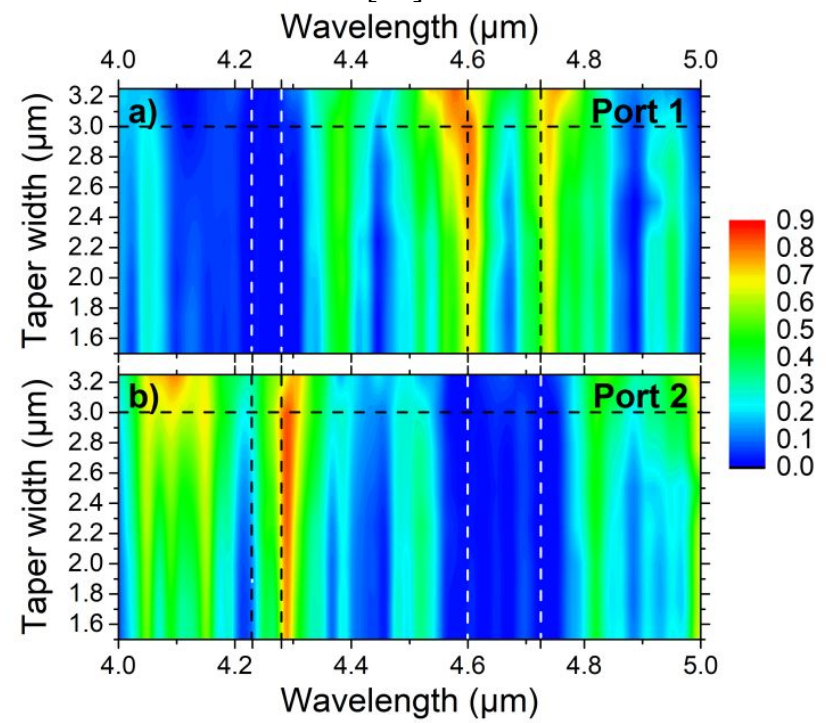

Fig. 8. Wavelength dependence of a) Port 1 and b) Port 2 transmission as a function of input and output ports taper width $\left(\mathrm{w}_{\text {taper }}\right)$.

The spectral dependence of transmission through both ports was calculated (Fig. 9) for a taper width of $\mathrm{w}_{\text {taper }}=3 \mu \mathrm{m}$ (represented by the horizontal dashed line in Fig. 8). From Fig. 9, it can be confirmed that tapering the output ports increases the overall transmission. In comparison to Fig. 7, it can also be observed that fabrication tolerances are relaxed even if the device may still be sensitive to variations larger than $\pm 100 \mathrm{~nm}$.

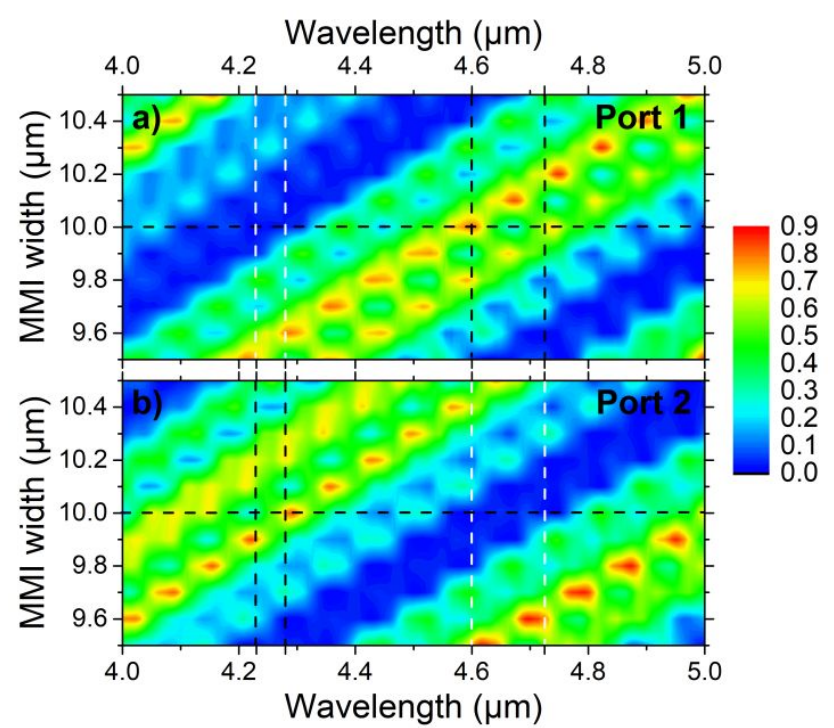

Fig. 9. Wavelength dependence of a) Port 1 and b) Port 2 transmission as a function of MMI multimode section width ( $\left.\mathrm{w}_{\mathrm{MMI}}\right)$ for an MMI with tapered input and output ports (taper width $=3 \mu \mathrm{m}$ ).

\section{IV.CONCLUSION}

In this paper, a $1 \times 2$ MMI beam splitter based on luminescent $\mathrm{Pr}^{3+}$-doped chalcogenides thin films and operating in the 4-5.5- $\mu \mathrm{m}$ wavelength range was investigated. This device relates on restricted interferences mechanism to multiplex $\mathrm{Pr}^{3+}$ luminescence on two spectral bands overlapping $\mathrm{CO}_{2}$ and $\mathrm{CO}$ absorption bands. The device was 
designed to be scarcely affected by imperfections occuring during processing steps (chalcogenide glass target fabrication and amorphous chalcogenide thin film deposition, photolithography, ICP-RIE etching). Optimum MMI dimensions were calculated and sensibility to refractive index, MMI multimode section width and length variations were studied. Finally, MMI ports tapering were implemented to enhance the device transmission.

The proposed combination of luminescent amorphous chalcogenides thin films with spectroscopic elements could enable the development of on-chip mid-IR multi-gas sensing devices providing low-cost solution for on-field chemical analysis.

The operating principle of the device can be extended to other gases $\left(\mathrm{NO}_{\mathrm{x}}, \mathrm{CH}_{4}, \mathrm{H}_{2} \mathrm{O} \ldots\right)$ displaying mid-IR absorption overlapping the broadband luminescence of Praseodymium ions but also to other rare-earth ions. Different mid-IR emission bands may be available in order to expand the operational range of this sensing device in terms of accessible wavelengths and target gases.

\section{ACKNOWLEDGMENT}

L.B., Y.D. and J.C. acknowledge financial support from Lannion Trégor Communauté, CD22, Region Bretagne and CPER SOPHIE. V.N. and P.N. are thankful to Czech Science Foundation (project No. 19-24516S).

\section{REFERENCES}

[1] M. Sieger and B. Mizaikoff, "Toward On-Chip Mid-Infrared Sensors", Anal. Chem., vol 88, no 11, pp 5562-5573, Apr. 2016, DOI: 10.1021/acs.analchem. 5 b04143

[2] P. Su, Z. Han, D. Kita, P. Becla, H. Lin, S. Deckoff-Jones, K. Richardson, L. C. Kimerling, J. Hu, and A. Agarwal, "Monolithic on-chip mid-IR methane gas sensor with waveguide-integrated detector", Appl. Phys. Lett., vol 114, no 5, pp 051103-1-051103-4, Feb. 2019, DOI: $10.1063 / 1.5053599$

[3] E. Baudet, A. Gutierrez-Arroyo, M. Baillieul, J. Charrier, P. Němec, L. Bodiou, J. Lemaitre, E. Rinnert, K. Michel, B. Bureau, J. L. Adam and V. Nazabal, "Development of an evanescent optical integrated sensor in the mid-infrared for detection of pollution in groundwater or seawater", $A d v$. Device Mater., vol 3, no 2, pp 23-29, Jun. 2017, DOI: $10.1080 / 20550308.2017 .1338211$

[4] Y.-C. Chang, P. Wägli, V. Paeder, A. Homsy, L. Hvozdara, P. van der Wal, J. Di Francesco, N. F. de Rooij and H. P. Herzig, "Cocaine detection by a mid-infrared waveguide integrated with a microfluidic chip ", Lab Chip, vol. 12, no 17, pp 3020-3023, Jun 2012, DOI: 10.1039/C2LC40601B

[5] R. Chandrasekar, Z. J. Lapin, A. S. Nichols, R. M. Braun, and A. W. Fountain III, "Photonic integrated circuits for Department of Defenserelevant chemical and biological sensing applications: state-of-the-art and future outlooks", Opt. Eng., vol 58, no 2, pp 020901-1-020901-11, Feb. 2019, DOI: $10.1117 / 1$. OE.58.2.020901

[6] P. T. Lin, H.-Y. G. Lin, Z. Han, T. Jin, R. Millender,L. C. Kimerling, and A. Agarwal, "Label-Free Glucose Sensing Using Chip-Scale MidInfrared Integrated Photonics", Adv. Opt. Mater., vol 4, no 11, pp 1755-1759, Nov. 2016, DOI: $10.1002 /$ adom.201600440

[7] M. Carras, G. Maisons, B. Simozrag, V. Trinite, M. Brun, G. Grand, P. Labeye, S. Nicoletti, "Monolithic tunable single source in the mid-IR for spectroscopy", Proc. SPIE 8631, Quantum Sensing and Nanophotonic Devices X, 863113 (4 February 2013); DOI: 10.1117/12.2009282

[8] C. Tsay, F. Toor, C. F. Gmachl, and C. B. Arnold, "Chalcogenide glass waveguides integrated with quantum cascade lasers for on-chip mid-IR photonic circuits", Opt. Lett., vol. 35, no. 20, pp. 3324-3326 (2010), DOI: 10.1364/OL.35.003324

[9] J. G Coutard, M. Brun, M. Fournier, O. Lartigue1, F. Fedeli, G. Maisons, J. M Fedeli, S. Nicoletti, M. Carras, and L. Durafourg, "Volume fabrication of Quantum Cascade Lasers on $200 \mathrm{~mm}$-CMOS pilot line", Sci. Rep., vol 10, 6185 (2020), DOI: 10.1038/s41598-020-63106-4

[10] V. Singh, P. T. Lin, N. Patel, H. Lin, L. Li, Y. Zou, F. Deng, C. Ni, J. Hu, J. Giammarco, A.P. Soliani, B. Zdyrko, I. Luzinov, S. Novak, J. Novak, P. Wachtel, S. Danto, J.D. Musgraves, K. Richardson, L.C.
Kimerling and A.M. Agarwal, "Mid-infrared materials and devices on a Si platform for optical sensing", Sci. Technol. Adv. Mater., vol. 15, no 1, pp 014603 (2014), DOI:10.1088/1468-6996/15/1/014603

[11] H. Lin, Z. Luo, T. Gu, L.C. Kimerling, K. Wada, A. Agarwal, and J. Hu, "Mid-infrared integrated photonics on silicon: a perspective", Nanophotonics, vol. 7, no 2 (2017), DOI: 10.1515/nanoph-2017-0085

[12] H. Podmore, A. Scott, P. Cheben, A. V. Velasco, J. H. Schmid, M. Vachon, and R. Lee, "Demonstration of a compressive-sensing Fouriertransform on-chip spectrometer", Opt. Lett., vol. 42, no. 7, pp. 1440-1443, 2017, DOI: $10.1364 /$ OL. 42.001440

[13] M. Nedeljkovic, A. V. Velasco, A. Z. Khokhar, A. Delâge, P. Cheben, and G. Z. Mashanovich, "Mid-Infrared Silicon-on-Insulator Fourier-Transform

Spectrometer Chip", IEEE Photon. Technol. Lett., vol. 28, no. 4, pp 528-531 (2016), DOI: 10.1109/LPT.2015.2496729

[14] Q. Liu, J. M. Ramirez, V. Vakarin, X. Le Roux, C. Alonso-Ramos, J. Frigerio, A. Ballabio, E.Talamas Simola, D. Bouville, L. Vivien, G. Isella, and D. Marris-Morini, "Integrated broadband dual-polarization Ge-rich SiGe mid-infrared Fourier-Transform spectrometer", Opt. Lett., vol. 43, no. 20, pp. 5021-5024 (2018), DOI:10.1364/OL.43.005021

[15] M. Montesinos-Ballester, Q. Liu, V. Vakarin, J. M. Ramirez, C. Alonso-Ramos, X. Le Roux, J. Frigerio, A. Ballabio, E. Talamas, L. Vivien, G. Isella, and D. Marris-Morini "On-chip fourier-transform spectrometer based on spatial heterodyning tuned by thermooptic effect", Sci. Reports, vol. 9, p 14633 (2019), DOI: 10.1038/s41598-019-50947-x

[16] X. Nie, F. Ryckeboer, G. Roelkens, R. Baets, "CMOS-compatible broadband co-propagative stationary Fourier transform spectrometer integrated on a silicon nitride photonics platform”, Opt. Express vol. 25, no. 8, pp A409-A418 (2017), DOI: 10.1364/OE.25.00A409

[17] D. Pohl, M. Reig Escalé, M. Madi, F. Kaufmann, P. Brotzer, A. Sergeyev, B. Guldimann, P. Giaccari, E. Alberti, U. Meier and R. Grange, "An integrated broadband spectrometer on thin-film lithium niobate", Nat. Photonics, vol. 14, pp 24-29 (2020), DOI:10.1038/s41566-019-0529-9

[18] A. Malik, M. Muneeb, S. Pathak, Y. Shimura, J. Van Campenhout, R.Loo, and G. Roelkens, "Germanium-on-Silicon Mid-Infrared Arrayed Waveguide Grating Multiplexers", IEEE Photon. Technol. Lett., vol. 25, no. 18, pp 1805-1808 (2013), DOI: 10.1109/LPT.2013.2276479

[19] A. Koshkinbayeva, P. Barritault, S. Ortiz, S. Boutami, M. Brun, J.M. Hartmann, P. Brianceau, O. Lartigue, F. Boulila, R.Orobtchouk, and P. Labeye, "Impact of Non-Central Input in N $\times$ M Mid-IR Arrayed Waveguide Gratings Integrated on Si”, IEEE Photon. Technol. Lett., vol. 28, no. 20, pp 2191-2194 (2016), DOI: 10.1109/LPT.2016.2587386

[20] P. Barritault, M. Brun, P. Labeye, J.-M. Hartmann, F. Boulila, M. Carras and S. Nicoletti, "Design, fabrication and characterization of an AWG at $4.5 \mu \mathrm{m}$ ", Opt. Express, vol. 23, no. 20, pp 26168- 26181 (2015), DOI: 10.1364/OE.23.026168

[21] A. Malik, M. Muneeb, Y. Shimura, J. Van Campenhout, R. Loo, and G. Roelkens, "Germanium-on-silicon planar concave grating wavelength (de)multiplexers in the mid-infrared", Appl. Phys. Lett., vol. 103, no. 16, p 161119 (2013), DOI: $10.1063 / 1.4826114$

[22] E. Ryckeboer, A. Gassenq, M. Muneeb, N. Hattasan, S. Pathak, L. Cerutti, J.B. Rodriguez, E. Tournie, W. Bogaerts, R. Baets, and G. Roelkens, "Silicon-on-insulator spectrometers with integrated GaInAsSb photodiodes for wide-band spectroscopy from 1510 to $2300 \mathrm{~nm}$ ", Opt. Express, vol. 21 , no. 5, pp 6101-6108 (2013), DOI: 10.1364/OE.21.006101

[23] C. Gilles, L. J. Orbe, G. Carpintero, G. Maisons, and M. Carras, "Mid-infrared wavelength multiplexer in $\mathrm{InGaAs} / \mathrm{InP}$ waveguides using a Rowland circle grating", Opt. Express, vol. 23, no. 16, pp 20288-20196 (2015), DOI: 10.1364/OE.23.020288

[24] J. Xiao, X. Liu, and X. Sun, "Design of an ultracompact MMI wavelength demultiplexer in slot waveguide structures", Opt. Express, vol. 15 , no. 13 , pp 8300-8308 (25 June 2007), DOI: 10.1364/OE.15.008300

[25] M. Rouifed, C. Littlejohns, G. Tina, H. Qiu, J. Penades, M. Nedeljkovic, Z. Zhang, C. Liu, D. Thomson, G. Mashanovich, G. Reed, and H. Wang, "Ultra-compact MMI-based beam splitter demultiplexer for the NIR/MIR wavelengths of $1.55 \mu \mathrm{m}$ and $2 \mu \mathrm{m}$," Opt. Express, vol. 25 , no. 10, pp 10893-10900 (2017), DOI: 10.1364/OE.25.010893

[26] A. Sánchez-Postigo, J. Gonzalo Wangüemert-Pérez, R. Halir, A. Ortega-Moñux, C. A. Alonso-Ramos, Í. Molina-Fernández, J. Soler Penadés, M. Nedeljkovic, G. Z. Mashanovich, P. Cheben, "A subwavelength structured multimode interference coupler for the 3-4 micrometers midinfrared band", Proc. SPIE 9516, Integrated Optics: Physics and Simulations II, 95160L (1 May 2015), DOI: 10.1117/12.2179454

[27] Y. Hu, T. Li, D. J. Thomson, X. Chen, J. Soler Penades, A. Z. Khokhar, C. J. Mitchell, G. T. Reed, and G. Z. Mashanovich, "Mid-infrared wavelength division (de)multiplexer using an interleaved angled multimode interferometer on the silicon-on-insulator platform", Opt. Lett., vol. 39, no. 6, pp. 1406-1409 (2014), DOI:10.1364/OL.39.001406 
[28] Y. Wei, G. Li, Y. Hao, Y. Li, J. Yang, M. Wang, and X. Jiang, "Long-wave infrared $1 \times 2$ MMI based on air-gap beneath silicon rib waveguides", Opt. Express, vol. 19, no. 17, pp. 15803-15809, (2011), DOI: 10.1364/OE.19.015803

[29] H.-D. Kenchington Goldsmith, N. Cvetojevic, M. Ireland, and S. Madden, "Fabrication tolerant chalcogenide mid-infrared multimode interference coupler design with applications for Bracewell nulling interferometry", Opt. Express, vol. 25, no. 4, pp 3038-3051 (2017), DOI: 10.1364/OE.25.003038

[30] L. Bodiou, F. Starecki, J. Lemaitre, V. Nazabal, J.-L. Doualan, Emeline Baudet, R. Chahal, A. Gutierrez-Arroyo, Y. Dumeige, I. Hardy, A. Braud, R. Soulard, P. Camy, P. Němec, G. Palma, F. Prudenzano, J. Charrier, "Mid-infrared guided photoluminescence from integrated Pr3+-doped selenide ridge waveguides", Opt. Mater., vol. 75, pp. 109-115 (January 2018), DOI: $10.1016 /$ j.optmat.2017.10.001

[31] V. Nazabal, F. Starecki, J.-L. Doualan, P. Nemec, P. Camy, H. Lhermite, L. Bodiou, M.L. Anne, J. Charrier, J.L. Adam, "Luminescence at $2.8 \mathrm{~mm}$ : Er3+-doped chalcogenide micro-waveguide”, Opt. Mater., vol. 58, pp. 390-397 (August 2016), DOI: 10.1016/j.optmat.2016.06.009

[32] J. A. Frantz, J. D. Myers, L. B. Shaw, J. S. Sanghera, "Integrated Optic Waveguides in Gallium Lanthanum Sulfide Glass for Mid-IR Applications", Proc. SPIE 10100, Optical Components and Materials XIV, 101000T (16 February 2017); doi: 10.1117/12.2253035

[33] F. Starecki, A. Braud, N. Abdellaoui, J. L. Doualan, C. BoussardPlédel, B. Bureau, P. Camy, and V. Nazabal, "7 to $8 \mu \mathrm{m}$ emission from Sm3+ doped selenide fibers", Opt. Express, vol 26, no 20, pp 26462-26469 (2018), DOI: $10.1364 / \mathrm{OE} .26 .026462$

[34] F. Starecki, G. Louvet, J. Ari, A. Braud, J. L. Doualan, R. Chahal, I. Hafienne, C. Boussard-Plédel, V. Nazabal, and P. Camy, "Dy3+ doped GaGeSbSe fiber long-wave infrared emission," J. Lumin., vol 218, p 116853 (2020), DOI: 10.1016/j.jlumin.2019.116853

[35] M. Shen, D. Furniss, M. Farries, D. Jayasuriya, Z. Tang, L. Sojka, S. Sujecki, T. M. Benson, and A. B. Seddon, "Experimental observation of gain in a resonantly pumped $\operatorname{Pr} 3+-$ doped chalcogenide glass mid-infrared fibre amplifier notwithstanding the signal excited-state absorption", Sci. Rep., vol 9, p 11426 (2019). DOI: 10.1038/s41598-019-47432-w

[36] J. Ari, F. Starecki, C. Boussard-Plédel, Y. Ledemi, Y.Messaddeq, J. L. Doualan, A. Braud, B. Bureau, and V. Nazabal, "Co-doped Dy ${ }^{3+}$ and $\mathrm{Pr}^{3+} \mathrm{Ga}_{5} \mathrm{Ge}_{20} \mathrm{Sb}_{10} \mathrm{~S}_{65}$ fibers for mid-infrared broad emission," Opt. Lett., vol 43, no. 12, pp 2893-2896 (2018), DOI: 10.1364/OL.43.002893.

[37] I. A. Schultz, C. S. Goldenstein, R. Mitchell Spearrin, J. B. Jeffries, and R. K. Hanson, "Multispecies Midinfrared Absorption Measurements in a Hydrocarbon-Fueled Scramjet Combustor", J. Propul. Power, vol. 30, no. 6, pp 1595-1604 (November-December 2014), DOI: 10.2514/1.B35261

[38] L. B. Soldano and E. C. M. Pennings, "Optical multi-mode interference devices based on self-imaging: principles and applications", J. Lightwave Technol., vol. 13, no. 4, pp. 615-627, April 1995, DOI: 10.1109/50.372474.

[39] E. Baudet, A. Gutierrez-Arroyo, P. Němec, L. Bodiou, J. Lemaitre, J. Charrier, O. De Sagazan, H. Lhermitte, E. Rinnert, K. Michel, B. Bureau, V. Nazabal, "Selenide sputtered films development for MIR environmental sensor", Opt. Mater. Express, vol. 6, no. 8, pp. 2616-2627 (2016), DOI: 10.1364/OME.6.002616

[40] L. Bodiou, J. Lemaitre, G. Louvet, S. Normani, E. Baudet, F. Starecki, J. -L. Doualan, Y. Dumeige, I. Hardy, A. Braud, P. Camy, P. Nemec, G. Palma, F. Prudenzano,V. Nazabal, J. Charrier "Design of a midinfrared multispecies gas sensor based on $\mathrm{Pr} 3+-$ doped chalcogenides waveguides," 2019 Photonics North (PN), Quebec City, QC, Canada, 2019, pp. 1-1. DOI: $10.1109 /$ PN.2019.8819593

[41] P. Nemec, M. Olivier, E. Baudet, A. Kalendova, P. Benda, and V. Nazabal, "Optical Properties of $\left(\mathrm{GeSe}_{2}\right)_{100-\mathrm{x}}\left(\mathrm{Sb}_{2} \mathrm{Se}_{3}\right)_{\mathrm{x}}$ Glasses in Near- and Middle-Infrared Spectral Regions", Mater. Res. Bull., vol. 51, pp 176-179 (March 2014), DOI: 10.1016/j.materresbull.2013.11.050

[42] J. Kischkat, S. Peters, B. Gruska, M. Semtsiv, M. Chashnikova, M. Klinkmüller, O. Fedosenko, S. Machulik, A. Aleksandrova, G. Monastyrskyi, Y. Flores, and W. T. Masselink, "Mid-infrared optical properties of thin films of aluminum oxide, titanium dioxide, silicon dioxide, aluminum nitride, and silicon nitride", Appl. Opt., vol. 51, no. 28 pp. 67896798 (2012), DOI: 10.1364/AO.51.006789

[43] Y. Wang, S. Qi, Z. Yang, R.Wang, A. Yang, P. Lucas, "Composition dependences of refractive index and thermo-optic coefficient in Ge-As-Se chalcogenide glasses", J. Non-Cryst. Solids, vol. 459, pp 88-93 (1 March 2017), DOI: 10.1016/j.jnoncrysol.2017.01.004

[44] Y. Fang, D. Furniss, D. Jayasuriya, H. Parnell, Z. Tang, A.B Seddon, and T.M. Benson, "Determining the continuous thermo-optic coefficients of chalcogenide glass thin films in the MIR region using FTIR transmission spectra", Opt. Express, vol. 27, no. 16, pp. 22275-22288 (2019) DOI: $10.1364 / \mathrm{OE} .27 .022275$
[45] W. Bogaerts and L. Chrostowski, "Silicon Photonics Circuit Design: Methods, Tools and Challenges", Laser Photonics Rev., vol 12, no 4, p 1700237(2018), DOI: 10.1002/lpor.201700237

[46] D. J. Thomson, Y. Hu, G. T. Reed, and Jean-Marc Fedeli, "Low Loss MMI Couplers for High Performance MZI Modulators", IEEE Photon. Technol. Lett., vol. 22, no. 20, pp 1485-1487, Oct. 2010, DOI: 10.1109/LPT.2010.

[47] M. T. Hill, X. J. M. Leijtens, G. D. Khoe, and M. K. Smit "Optimizing Imbalance and Loss in $223-\mathrm{dB}$ Multimode Interference Couplers via Access Waveguide Width", J. Lightwave Technol., vol. 21, no. 10, pp. 2305-2313, Oct. 2005, DOI: 10.1109/JLT.2003.818164

Loïc Bodiou received his $\mathrm{PhD}$ from the University of Caen (France) in 2007. This work was focused on the luminescence of rare earth ions in nitride semiconductors. He was appointed as associate professor at University of Rennes 1 in 2009. His current research interests are related to the design, technological processing and optical characterizations of photonic integrated circuits based on (rare earth-doped) chalcogenides for optical signal processing, IR and mid-IR light sources or sensing applications.

Yannick Dumeige graduated from the Ecole Supérieure d'Optique, Orsay, France, in 1999 and received the Ph.D degree from the University of Paris XI, Orsay in 2002. In 2002 he spent one year at Laboratoire de Photonique Quantique et Moléculaire and Ecole Normale Supérieure de Cachan (France) as a postdoctoral research and teaching assistant. In 2003 he joined the University of Rennes 1 as an associate professor. In 2013, he was nominated Junior Member of the Institut Universitaire de France. His current research interests are integrated nonlinear optics, optical micro-cavities and sensors.

Simone Normani Simone Normani obtained his B.Sc. in physics from the University of Trento in 2011, and went on to receive a M.Sc. in experimental physics at the same University in 2013, with specialization in disordered systems and nanomaterials, in collaboration with the CMSFO group at the CNR-IFN laboratory in Trento. He achieved his Ph.D. title in 2017 from the University of Caen, France, and held a postdoc position as specialist in inorganic materials at the Faculty of Chemical Technology of the University of Pardubice, Czech Republic, from 2018 to 2020 working on rare earth-doped chalcogenide glasses for MIR applications. $\mathrm{He}$ is now working as postdoc at the Center for Nano Science and Technology in Milan, with an interest in multilayer devices for bacterial sensing applications.

Geoffrey Louvet obtained a Bachelor's degree in Chemistry and in 2017 a Master's degree in Solid State and Materials Chemistry from the University of Rennes 1 (France). $\mathrm{He}$ is currently pursuing a $\mathrm{PhD}$ in Chemistry between the ISCR at the University of Rennes 1 and the COPL at Laval University, (Québec, Canada) under the cosupervision of Dr. V. Nazabal and Prof. Y. Messaddeq. He specializes in the study of the fluorescence of lanthanide ions in chalcogenide glasses, glass target preparation for sputtering and e-beam evaporation, and the anodic oxide glass-silicon bonding.

Petr Němec received his $\mathrm{PhD}$ degree in Chemistry and Technology of Inorganic Materials from University of Pardubice (2002). Since 2006, he worked as Associate Professor at Faculty of Chemical Technology, University of Pardubice. He became full Professor in 2015. He works in the 
field of inorganic glasses and amorphous thin films focusing of the thin films.

Virginie Nazabal, she received the B.S. and M.S. degrees in chemistry in 1996 from Ecole Normale Supérieure, University of Paris VI. She got her PhD degree in Solid State Chemistry and Material Sciences from the University of Bordeaux (France) in 1999. She joined the NIMS (Tsukuba, Japan) as JSPS post-doctoral fellowship in 2000. She has belonged to the CNRS as a permanent Researcher since 2001 and has been a Senior Researcher at CNRS since 2015. Her research activity is dedicated to vitreous materials for optics at the Institute of Chemical Sciences of the University of Rennes (France). She is currently exploring the potential offered by glass, thin films and fibers for photonic devices such as infrared optical sensors. She is co-author of 3 chapters of book and more than 175 peer-reviewed scientific articles. She received in 2010 a bronze medal of CNRS and a PollutecAdeme Award in 2011 for Innovative Techniques for the Environment.

Joël Charrier received the Ph.D. degree from the University of Rennes 1, France, in 2000. His dissertation was devoted to the study of light propagation in silicon-based nanostructured waveguides. Since 2000 , he has been with the FOTON Institute as assistant-professor at University of Rennes 1 . He is interested in photonic integrated circuits for optical communication and sensing applications. $\mathrm{He}$ is currently the head of the Guided Optics and Sensors research group (OGC-Optique Guidée et Capteurs) of FOTON Institute. 


\section{Table I}

\begin{tabular}{cc}
\hline \hline Parameter & Value \\
\hline Waveguide height $h$ & $1.25 \mu \mathrm{m}$ \\
Input port width $w$ & $1.5 \mu \mathrm{m}$ \\
Output port width $w$ & $1.5 \mu \mathrm{m}$ \\
Multimode section width $w_{M M I}$ & $10 \mu \mathrm{m}$ \\
Multimode section length $L_{M M I}$ & $519 \mu \mathrm{m}$ \\
Band 1 & $4.20-4.32 \mu \mathrm{m}$ \\
Band 2 & $4.50-4.86 \mu \mathrm{m}$ \\
\hline \hline
\end{tabular}


Figure 1

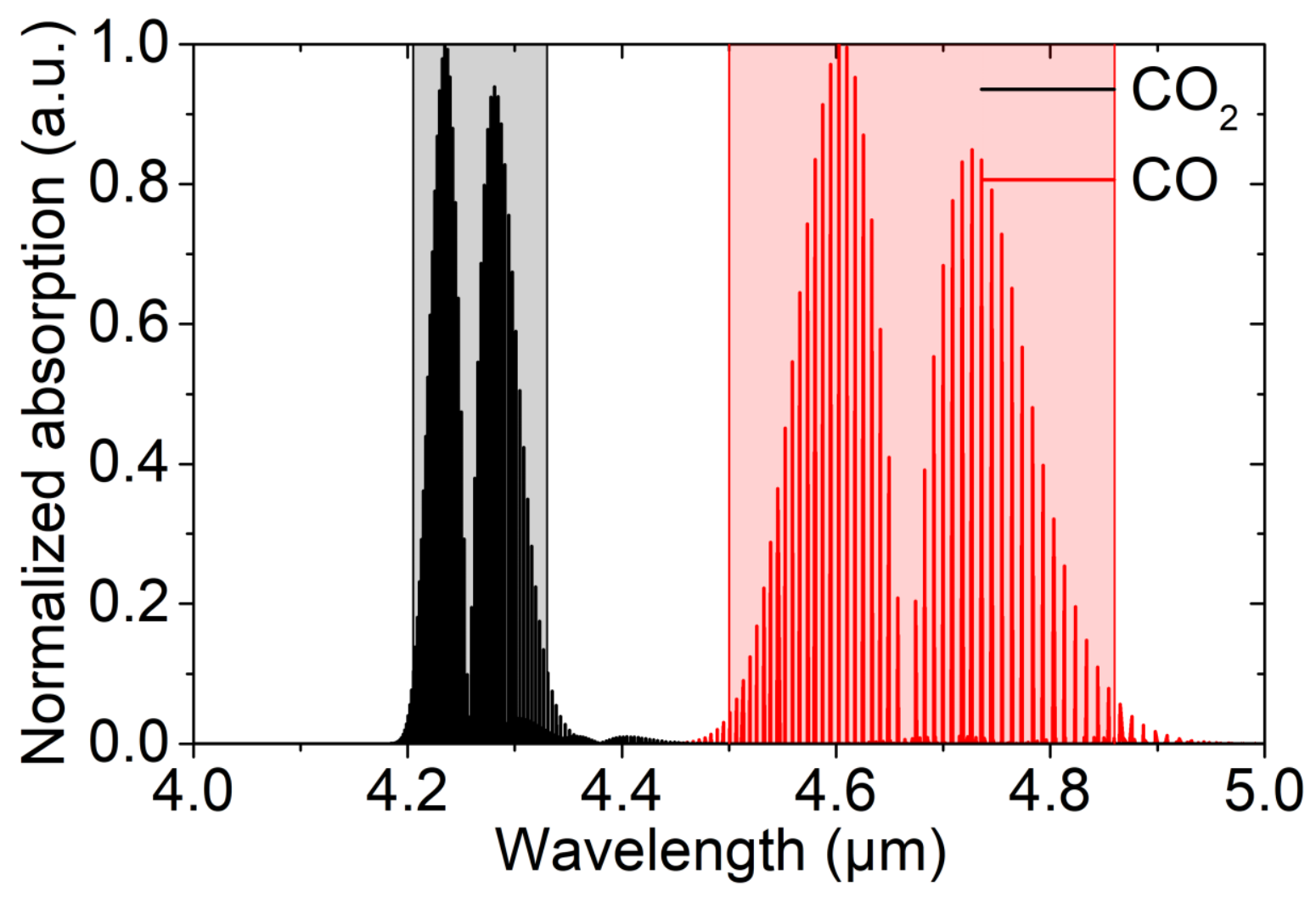


Figure 2

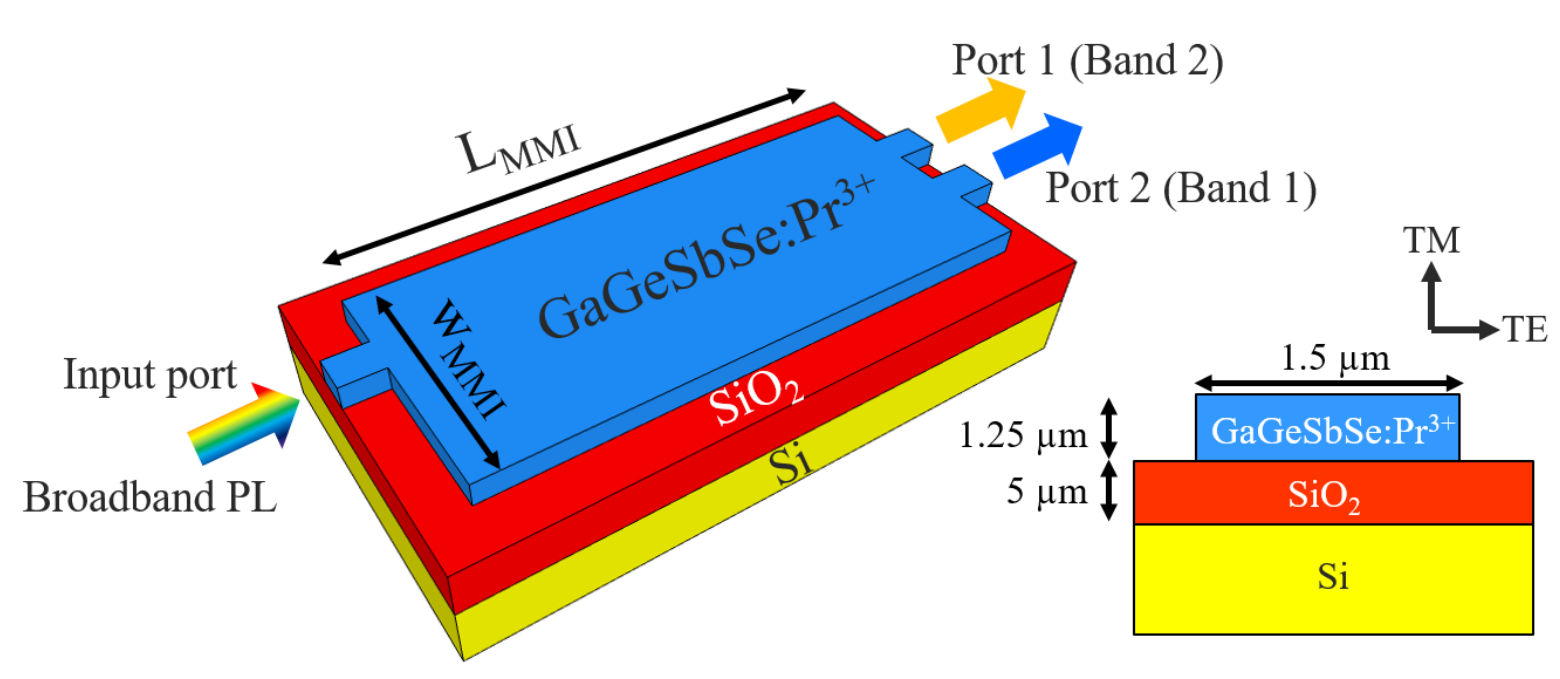


Figure 3

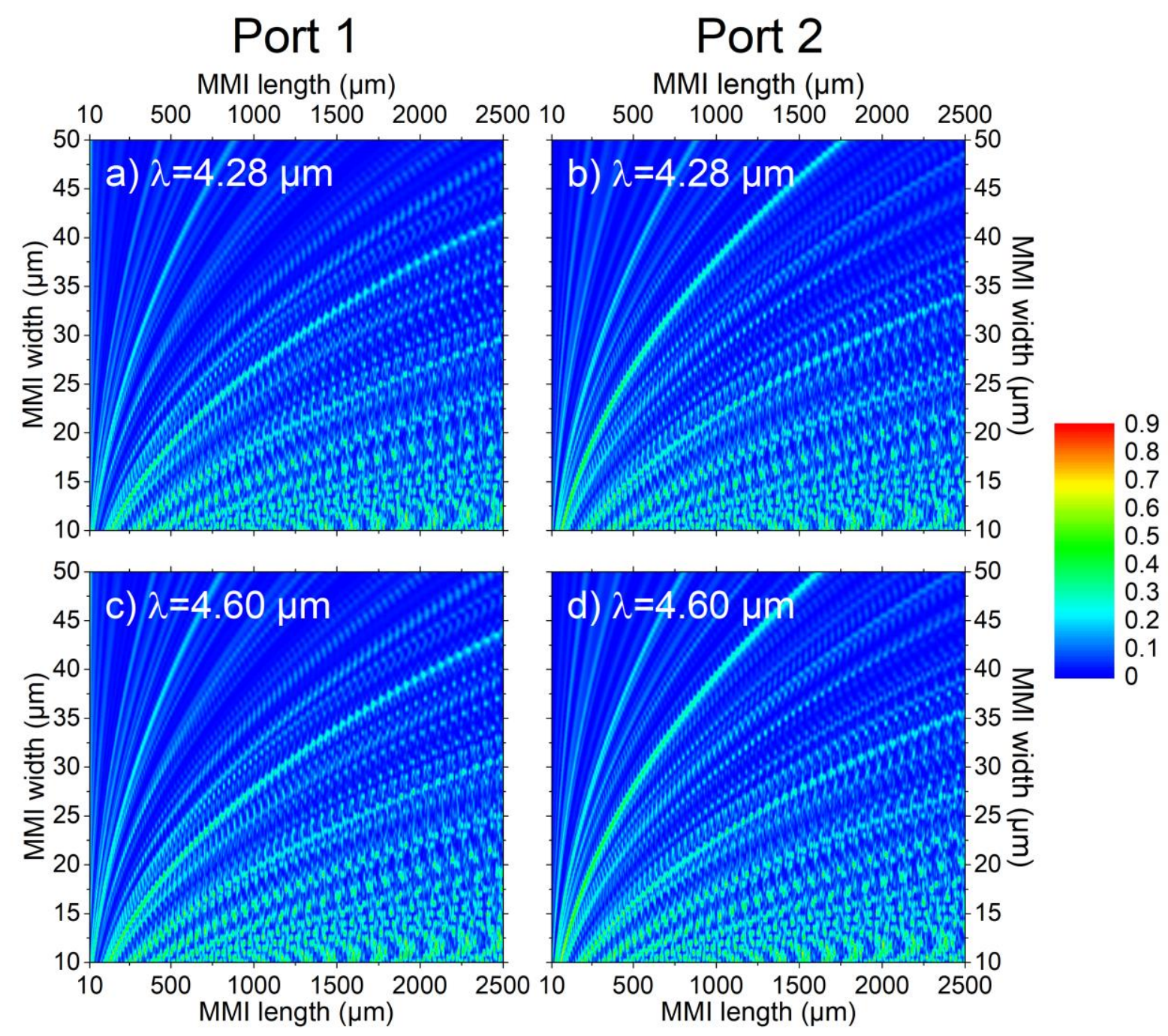


Figure 4
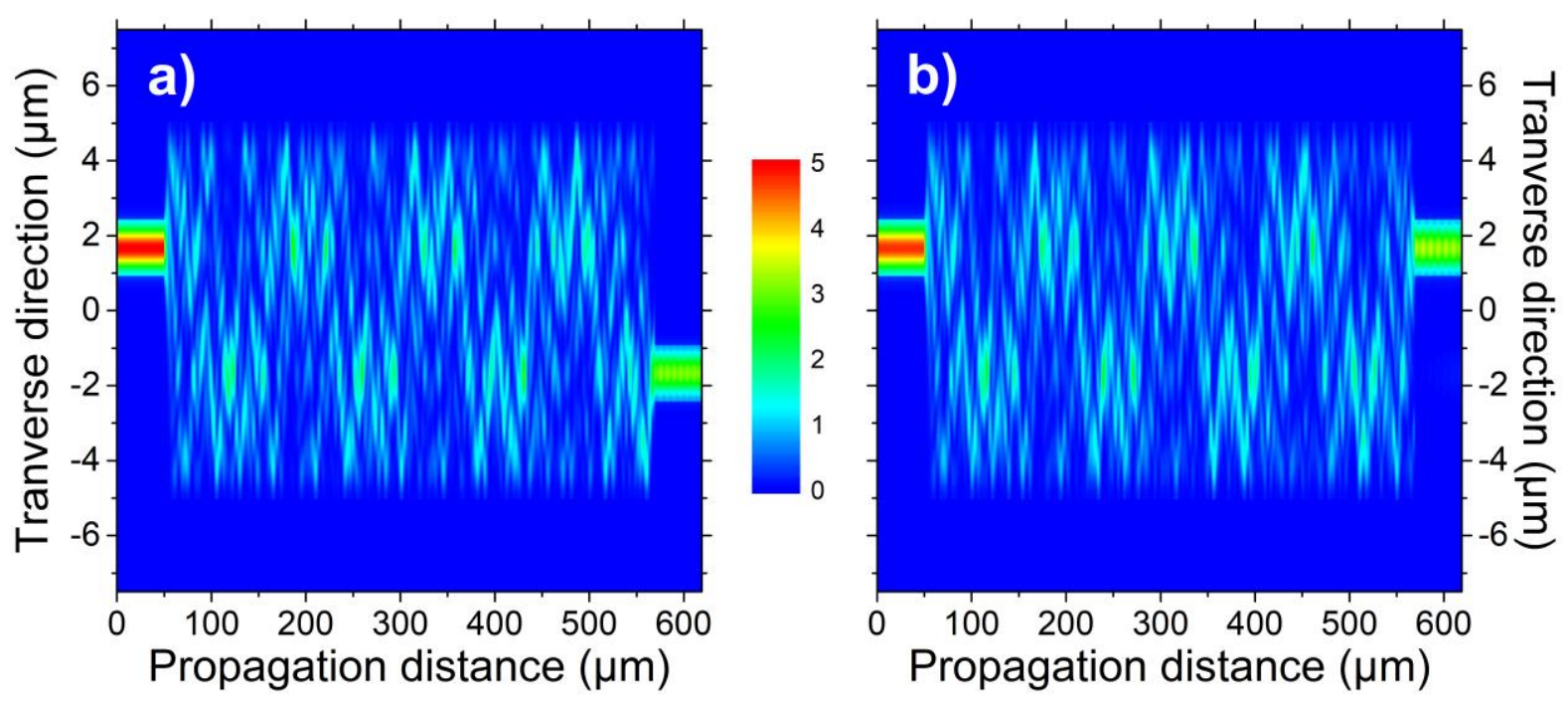
Figure 5

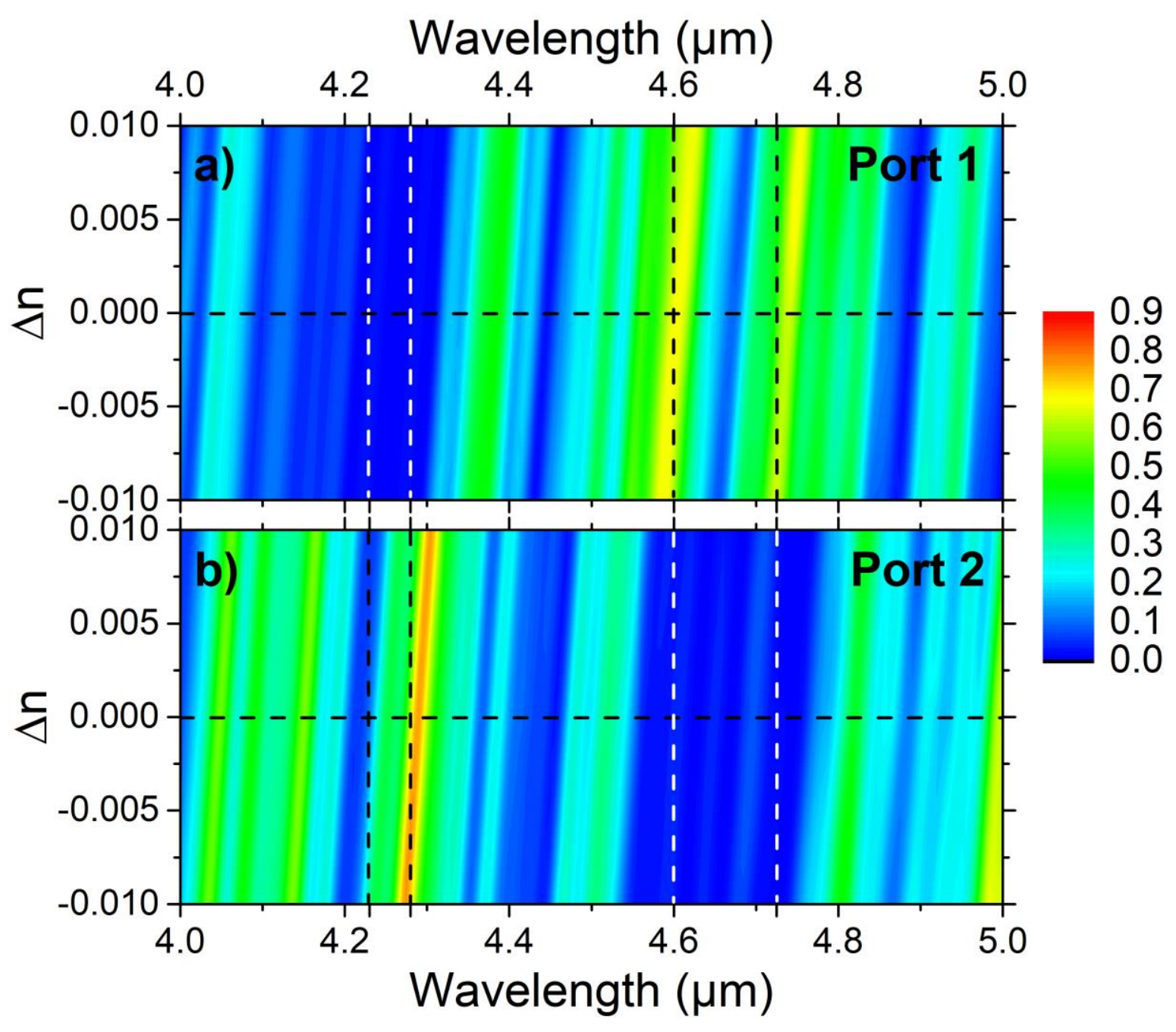


Figure 6

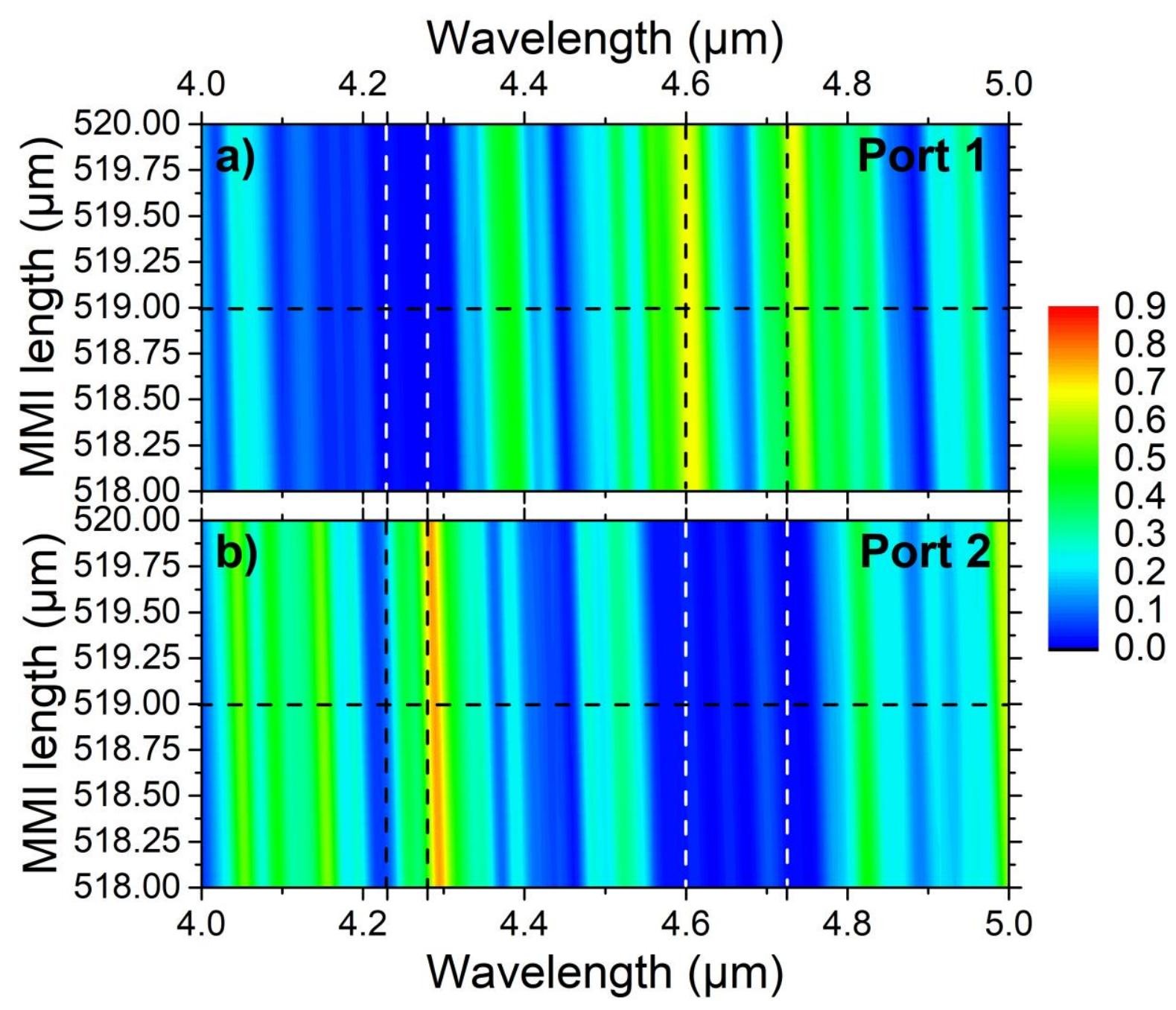


Figure 7

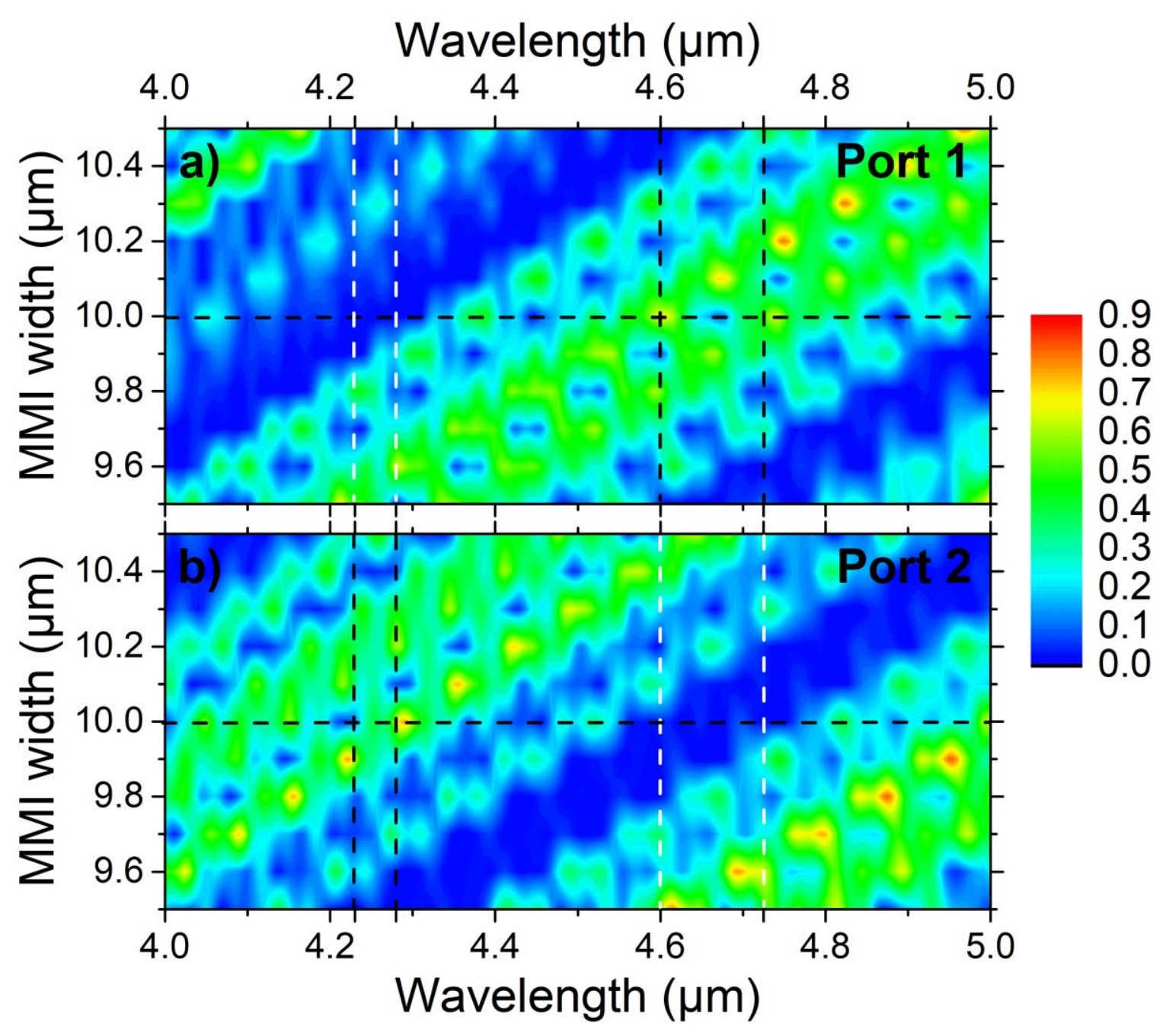


Figure 8

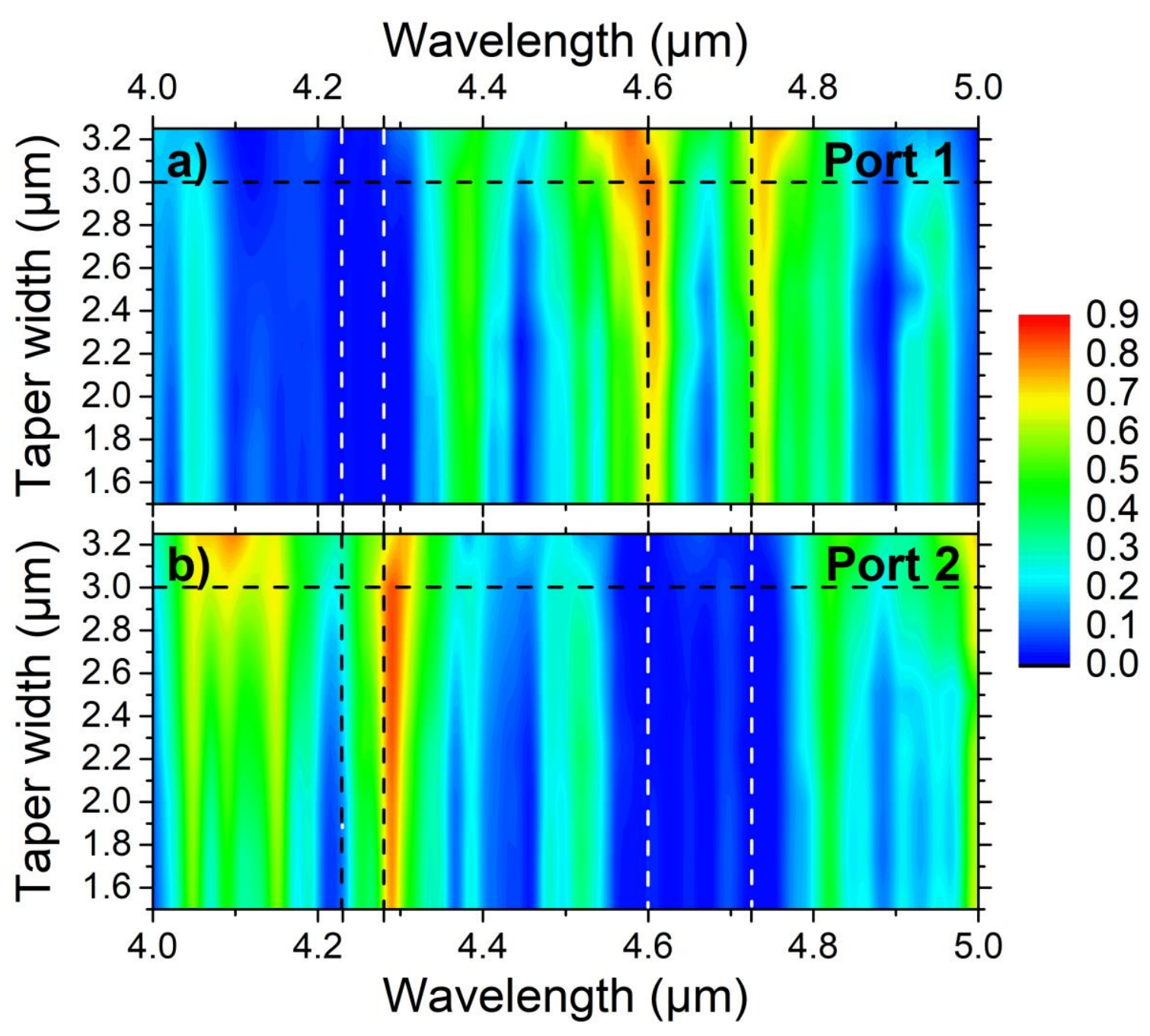


Figure 9

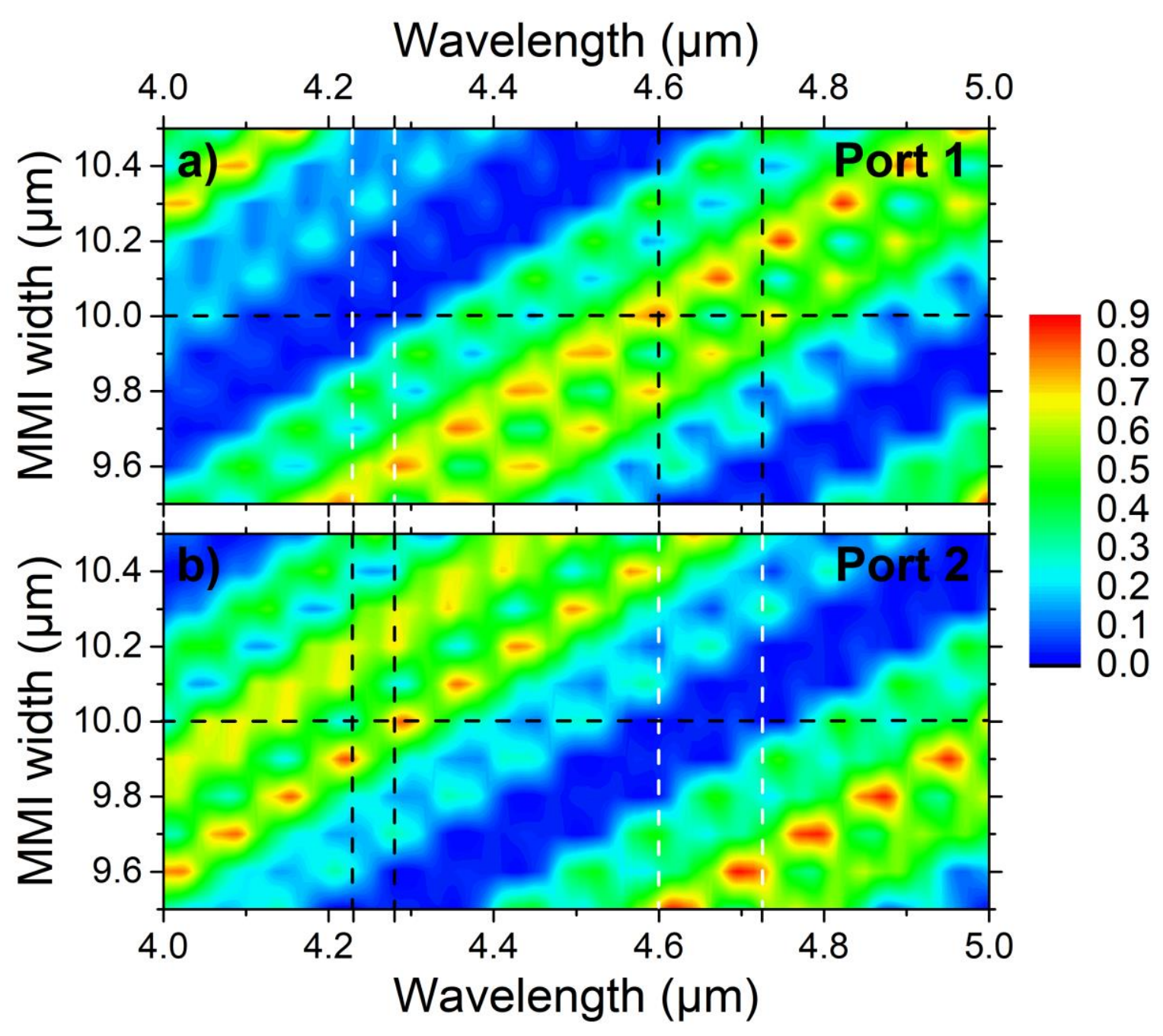




\section{Figures captions}

Fig. 1. Normalized absorption bands of carbon monoxide $(\mathrm{CO})$ and carbon dioxide $\left(\mathrm{CO}_{2}\right)$. The two bands to multiplex are superimposed to these spectra.

Fig. 2. Schematic representation of the multiplexing MMI structure based on GaGeSbSe:Pr ${ }^{3+}$. The cross-section of the input port is displayed on the right.

Fig. 3. Power transmission for the two output ports as a function of MMI multimode section width (wMMI) and length (L $\mathrm{L}_{\mathrm{MMI}}$ ) for two wavelengths: a), b) $4.28 \mu \mathrm{m}$ and c), d) $4.6 \mu \mathrm{m}$.

Fig. 4. Simulation of the power transmission for the MMI with optimized dimensions at a) $4.3 \mu \mathrm{m}$ and b) $4.6 \mu \mathrm{m}$.

Fig. 5. Wavelength dependence of a) Port 1 and b) Port 2 transmission as a function of chalcogenide film refractive index variations $(\Delta \mathrm{n})$ for optimized MMI multimode section dimensions. Vertical dashed lines correspond to absorption maxima of $\mathrm{CO}_{2}$ and $\mathrm{CO}$.

Fig. 6. Wavelength dependence of a) Port 1 and b) Port 2 transmission as a function of MMI multimode section length $\left(\mathrm{L}_{\mathrm{MMI}}\right)$.

Fig. 7. Wavelength dependence of a) Port 1 and b) Port 2 transmission as a function of MMI multimode section width ( $\mathrm{w}_{\text {MMI }}$ ) with straight input and output ports (ports width $=1.5 \mu \mathrm{m}$ ).

Fig. 8. Wavelength dependence of a) Port 1 and b) Port 2 transmission as a function of input and output ports taper width ( $\left.\mathrm{w}_{\text {taper }}\right)$.

Fig. 9. Wavelength dependence of a) Port 1 and b) Port 2 transmission as a function of MMI multimode section width ( (MMI $_{\text {I }}$ ) for an MMI with tapered input and output ports (taper width $=3 \mu \mathrm{m}$ ). 


\section{Table captions}

TABLE I :

LIST OF PARAMETERS OF OPTIMIZED MMI 